\title{
Downstream targets of transcription factor Pax6 in cortical development
}

\author{
Dissertation \\ zur Erlangung des Doktorgrades \\ der Mathematisch-Naturwissenschaftlichen Fakultäten \\ der Georg-August-Universität zu Göttingen
}

\author{
vorgelegt von \\ Sridhar Boppana \\ aus Vuyyuru, Indien
}

Göttingen 2007 
D 7

Referent:

Korreferent:

Tag der mündlichen Prüfung:
Prof. Dr. Ernst A Wimmer

Prof. Dr. Rüdiger Hardeland $31^{\text {st }}$ Oktober 2007 
This thesis is dedicated to the memory of my beloved mother

\section{Krishna Kumari Boppana}




\section{Contents}

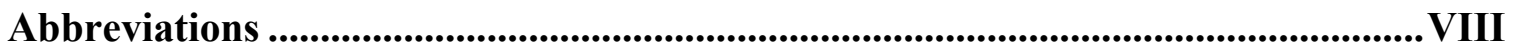

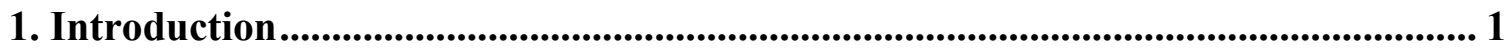

1.1 Development of the mouse cortex................................................................................... 1

1.2 Specification of the dorsal telencephalon.............................................................. 2

1.3 Signaling centers in patterning of cerebral cortex.................................................. 5

1.4 Transcription factor Pax6 in cortical development .............................................. 8

1.4.1 Structural and functional domains of Pax6 ..................................................... 8

1.4.2 Role of Pax6 in patterning of the brain................................................................ 8

1.4.3 Regulation of neurogenesis by Pax6 ................................................................. 10

1.4.4 Pax6 in eye development ............................................................................... 10

1.5 Cellular retinaldehyde-binding protein (CRALBP) .............................................. 11

1.6 Transcription factor AP-2 gamma ............................................................................... 13

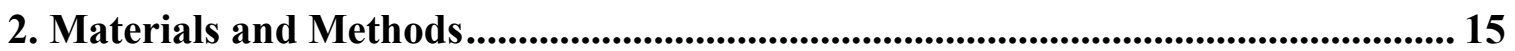

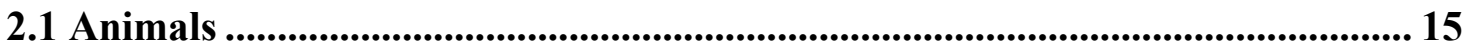

2.2 Molecular biology procedures .................................................................................. 15

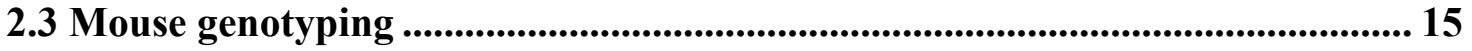

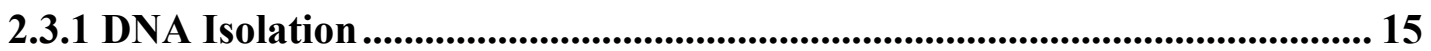

2.3.2 Polymerase chain reaction (PCR)...................................................................... 16

2.4 Preparation of Probes for In situ hybridization................................................... 19

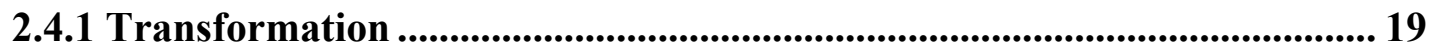

2.4.2 Plasmid isolation (mini prep)............................................................................. 20

2.4.3 Plasmid linearization and purification................................................................ 20

2.4.4 Synthesis of radioactive riboprobes ............................................................... 21

2.4.5 In situ Hybridization............................................................................................... 22

2.5 Chromatin Immunoprecipitation (ChIP) Assay ................................................... 25

2.6 Immunohistochemistry .......................................................................................... 26

2.7 Plasmid constructs and luciferase reporter assay .................................................. 26 


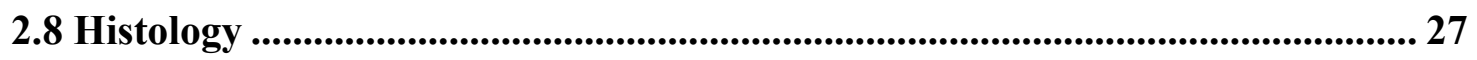

2.9 Image acquisition ............................................................................................................... 27

3. Aim of the project ….................................................................................................................. 28

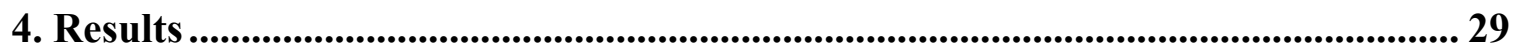

4.1 Analysis of CRALBP function in the cortex.......................................................... 29

4.1.1 Pax6 and CRALBP are coexpressed in several regions of the CNS.......... 30

4.1.2 Mutually exclusive expression domains of Pax6 and CRALBP in the eye35

4.1.3 Chromatin immunoprecipitation assay (ChIP) reveals Pax6 binding sites on CRALBP promoter.................................................................................................... 36

4.1.4 Pax6 activates CRALBP promoter in vitro ..................................................... 38

4.1.5 Expression of layer-specific markers indicates no lamination defects in

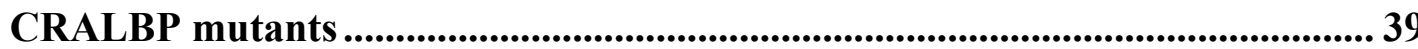

4.1.6 BLBP expressing radial glial processes show a 'wavy' morphology in mutants............................................................................................................................ 42

4.2 Analysis of AP2 $\gamma$ function in the cortex .......................................................... 46

4.2.1 Analysis of Cad8 and Id2 expression indicates a shift in Id2 expression

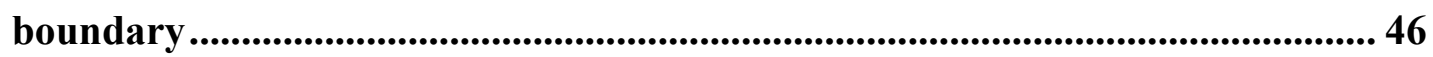

4.2.2 Expression of Cux2 and Svet1 does not change in the AP2 $\gamma$ mutants ...... 49 4.2.3 Expression of Er81 remains unchanged; expression of LMO4 is decreased

4.2.4 Lamination and proliferation in AP2 $\gamma$ mutants is not affected ..................52

4.2.5 Pax6 interacts directly with AP2 $\gamma$ promoter .................................................... 52

4.2.6 AP2 $\gamma$ does not influence morphology of radial glial processes expressing

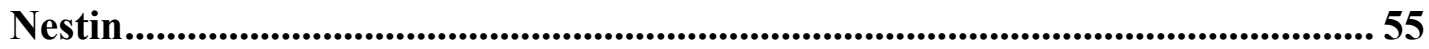

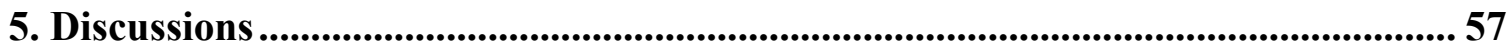

5.1 CRALBP is a direct downstream target of Pax6 and influences radial glial morphology

5.2 AP2 $\gamma$ does not regulate lamination and proliferation but might influence arealization of the cortex 


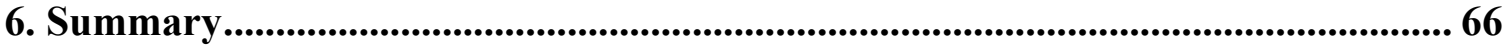

7. Conclusions....................................................................................................................... 68

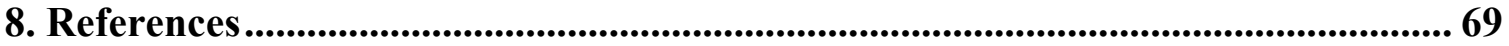

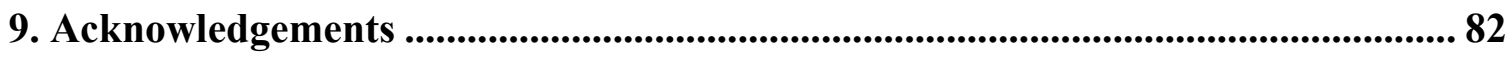

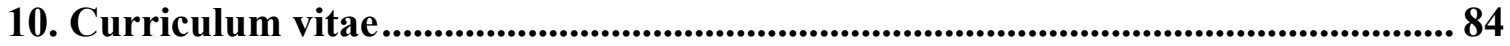




\section{Abbreviations}

\begin{tabular}{|c|c|}
\hline ADA & Adenosine deaminase \\
\hline AP2 & Activation protein 2 \\
\hline APC & Adenomatous polyposis coli \\
\hline $\operatorname{arRP}$ & Autosomal recessive retinitis pigmentosa \\
\hline bHLH & Basic helix-loop-helix \\
\hline BLBP & Brain lipid-binding protein \\
\hline BMP & Bone morphogenic protein \\
\hline BrdU & 5-bromo-2-desoxy-uridine \\
\hline $\mathrm{bp}$ & Base pair \\
\hline BSA & Bovine serum albumin \\
\hline $\mathrm{Cad}$ & Cadherin \\
\hline cDNA & Complementary DNA \\
\hline CDS & Coding sequence \\
\hline ChIP & Chromatin immunoprecipitation assay \\
\hline CNS & Central nervous system \\
\hline $\mathrm{CP}$ & Cortical plate \\
\hline CRALBP & Cellular retinaldehyde binding protein \\
\hline $\mathrm{CR}$ & Cajal retzius cells \\
\hline CUX & Cut domain transcription factor \\
\hline DAPI & 4'-6'-diamidino-2-phenylindole \\
\hline DEPC & Diethyl pyrocarbonate \\
\hline DNA & Deoxyribonucleic acid \\
\hline DNase & Deoxyribonuclease \\
\hline dNTP & Deoxynucleotides \\
\hline DTT & Dithiothreitol \\
\hline $\mathrm{E}$ & Embryonic day \\
\hline EDTA & Ethylene diamine tetra acetic acid \\
\hline FCS & Fetal calf serum \\
\hline
\end{tabular}


FGFR

Fig.

G1

G2

GABA

GAPDH

GFAP

hrs

HCL

HD

HPRT

HRP

IPC

IHC

IZ

ko

LB

LI

LP

LRAT

LRPs

LTR

$\mathrm{mAB}$

mRNA

MZ

n

$\mathrm{NaAc}$

$\mathrm{NaCl}$

NADPH

$\mathrm{NaOH}$

NE
Fibroblast growth factor receptor 1

Figure

G1-phase of cell cycle

G2-phase of cell cycle

$\gamma$-amino butyric acid

Glyceraldehyde-3-phosphate dehydrogenase

Glial fibrillary acidic protein

Hours

Hydrochloric acid

Homeodomain

Hypoxanthine guanine phosphoribosyl transferase

Horse radish peroxidase

Intermediate progenitor cell

Immunohistochemistry

Intermediate zone

Knock-out

Luria-Bertani

Labeling index

Lens placoid

Lecithin-retinol acyltransferase

Lipoprotein receptor-related proteins

Long terminal repeat

Monoclonal antibody

Messenger ribonucleic acid

Marginal zone

Sample number

Sodium acetate

Natrium chloride

Reduced nicotinamide adenine dinucleotide phosphate

Sodium hydroxide

Neuroepithelium 


\begin{tabular}{|c|c|}
\hline Ngn & Neurogenin \\
\hline NR & Neuroretina \\
\hline NTE & $\mathrm{NaCl}$-tris-EDTA \\
\hline $\mathrm{OC}$ & Optic cup \\
\hline ORE & Optic recess \\
\hline $\mathrm{OV}$ & Optic vesicle \\
\hline $\mathrm{P}$ & Postnatal day \\
\hline $\mathrm{pAB}$ & Polyclonal antibody \\
\hline PBS & Phosphate buffered saline \\
\hline $\mathrm{pBS} \mathrm{KS}$ & Plasmid bluescript KS \\
\hline PCR & Polymerase chain reaction \\
\hline pcDNA & Plasmid-cDNA \\
\hline $\mathrm{PD}$ & Paired domain \\
\hline PD5a & Paired domain containing exon5a \\
\hline Pen/Strep & Penicillin/Streptomycin \\
\hline PFA & Paraformaldehyde \\
\hline $\mathrm{PH} 3$ & Phosphorylated histone $\mathrm{H} 3$ \\
\hline PRD & Bipartite paired domain \\
\hline PSPB & Pallial-subpallial boundary \\
\hline RNA & Ribonucleic acid \\
\hline RNase & Ribonuclease \\
\hline $\mathrm{RC} 2$ & Radial cell 2 \\
\hline $\operatorname{rln}$ & Reelin \\
\hline $\mathrm{rpm}$ & Rounds per minute \\
\hline RT & Room temperature \\
\hline RPE & Retinal pigmented epithelium \\
\hline SDS & Sodium dodecyl sulfate \\
\hline s.d. & Standard deviation \\
\hline $\mathrm{SE}$ & Surface ectoderm \\
\hline siRNA & Small interfering RNA \\
\hline SP & Subplate \\
\hline
\end{tabular}




\begin{tabular}{ll} 
SP6 & Bacteriophage sp6 \\
SEM & Standard error of the mean \\
SFRP & Secreted frizzled related protein \\
Shh & Sonic hedgehog \\
S-phase & DNA-synthesis phase of the cell cycle \\
SSC & Sodium chloride-Sodium citrate \\
Svet1 & Subventricular tag1 \\
SVZ & Subventricular zone \\
T7 & Bacteriophage T7 \\
TAD & Transactivating domain \\
TAE & Tris-acetate-EDTA \\
TBE & Tris-borate-EDTA \\
TBS & Tris-buffered saline \\
Tbr & T-domain transcription factor \\
TGF & Transforming growth factor- $\beta$ \\
TF & Transcription factor \\
Tris & Tris-(hydroxymethyl)-aminomethane \\
Tween 20 & Polyoxyethylene sorbitan monolaurate \\
VZ & Ventricular zone \\
wt & Wild type \\
\hline
\end{tabular}




\section{Introduction}

\subsection{Development of the mouse cortex}

Specification of a group of cells of the presumptive ectoderm into the neural plate marks the beginning of development of the central nervous system (CNS). The neural plate then invaginates under the influence of signals from the notochord to give rise to the neural tube. After the initial induction of neural tissue, the telencephalon is formed at the rostralmost portion of the neural tube. It subdivides into two cerebral cortices. As development proceeds, signals from the anterior neural ridge in the rostral midline, the roof plate in the dorsal midline, the cortical hem, and the surface ectoderm ensure proper specification and patterning of the cortex.

The neural tube is composed of neuroepithelial cells, progenitors that line the ventricular lumen and form the ventricular zone (VZ). After the onset of cortical neurogenesis, neuroepithelial cells give rise to bipolar radial glial cells, the progenitors of cortical neurons and astrocytes. In contrast, progenitors in the retina and spinal cord mostly maintain neuroepithelial properties and to a lesser extent radial glial properties during neurogenesis. Almost all neurons in the brain are directly or indirectly derived from radial glia [Malatesta et al., 2003]. Neuroepithelial cells show interkinetic nuclear migration, with their nuclei undergoing mitosis at the apical surface of the ventricular zone. Radial glia are also known to exhibit astroglial properties [Kriegstein and Gotz, 2003] and express markers like glial fibrillary acidic protein (GFAP), vimentin, brain- 
lipid-binding protein (BLBP) and the calcium binding protein $\mathrm{S} 100 \beta$ during neurogenesis [Campbell and Gotz, 2002; Gotz, 2003; Kriegstein and Gotz, 2003].

Besides radial glial cells, basal progenitors are another class of neuronal progenitors that appear at the onset of neurogenesis [Miyata et al., 2004; Noctor et al., 2004; Smart, 1973]. VZ progenitors divide asymmetrically at the ventricular surface to self-renew and produce a rounded daughter cell called the Intermediate progenitor cell (IPC). These IPCs migrate away from the $\mathrm{VZ}$ to form the SVZ, where they extend multiple short processes. They are also called basal progenitors, and express markers like subventricular tag1 (Svet1), T-domain transcription factor (TF; Tbr2), and the homeobox proteins Cux1 and 2 [Englund et al., 2005; Nieto et al., 2004; Tarabykin et al., 2001; Zimmer et al., 2004]. Multipolar IPCs divide symmetrically at a nonsurface position to produce two immature multipolar neurons [Cai et al., 2002]. These immature neurons migrate into the cortical plate [Noctor et al., 2004] and differentiate into projection neurons. IPC's appear to produce the majority of neurons during early neurogenesis when deep layers are produced [Haubensak et al., 2004].

\subsection{Specification of the dorsal telencephalon}

After initial induction by extrinsic signals, the telencephalon is specified into dorsal (pallial) and ventral (subpallial) regions. This is mediated by basic helix-loop-helix (bHLH) transcription factors (TFs) like Ngn1 and Ngn2. Neurogenins promote cortical development by suppressing Mash1-dependent ventral fates [Fode et al., 2000]. The LIM homeobox gene Lhx2 further specifies the dorsal telencephalon into choroid plexus 
epithelium, cortical hem and cortical VZ. Signals from bone morphogenetic proteins (BMPs) in the dorsal midline roof further expand the cortical VZ [Monuki et al., 2001] and may also regulate patterning.

Before the onset of neurogenesis, transcription factors in the cortical neuroepithelium promote forebrain regionalization, patterning and progenitor proliferation, and suppress neuronal differentiation. The homeodomain (HD) TFs Emx1 and 2, and the paired and homeodomain TFs Pax6, Tlx, Ngn1 and 2 are among those contributing to regionalization [Muzio et al., 2002].

The cerebral cortex is composed of projection neurons that are glutamatergic and excitatory, and interneurons that are GABAergic and inhibitory. Cortical VZ progenitors become glutamatergic projection neurons of the cortex [Parnavelas, 2000] and often lack GABAergic markers. Cortical neurons are arranged in a cytoarchitecturally and functionally defined pattern with different layers exhibiting specific molecular properties. For instance, Er81 is expressed in some progenitor cells and, subsequently in a subset of layer 5 projection neurons, suggesting that Er81 may specify layer 5 fate [Hasegawa et al., 2004; Yoneshima et al., 2006]. Otx1 is also a deep layer marker and is expressed in neurons of layers 5/6 [Frantz et al., 1994]. Lmo4, a LIM homeodomain protein known to be expressed in layers 2, 3 and 5 [Bulchand et al., 2003], is a specific marker for type II pyramidal neurons [Arlotta et al., 2005]. Similarly, Cux2 is expressed in mitotically active SVZ cells and in upper layer neurons suggesting that it may specify upper layer fate [Nieto et al., 2004]. 
The Cajal-Retzius (CR) cells in the marginal zone (MZ) of the cortical primordium produce Reelin [Ogawa et al., 1995]. Reelin signals to radial glial cells and their daughter neurons [Magdaleno et al., 2002], and provides guidance for young neurons to migrate into the cortical plate.

(a)

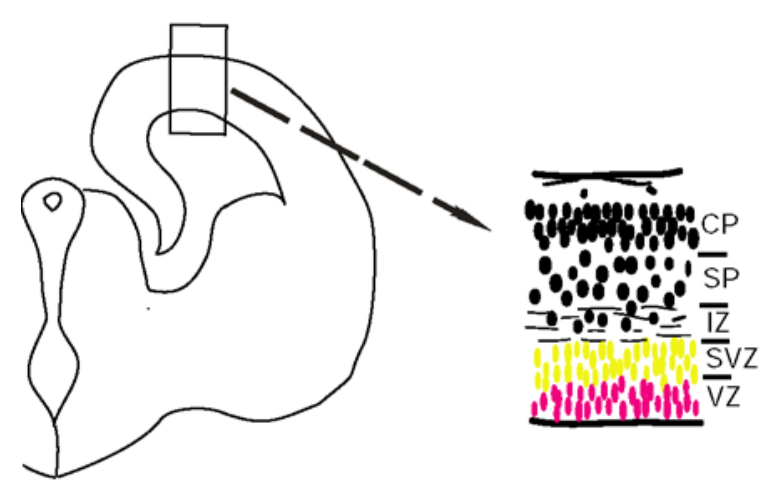

E14.5 cortex (b)

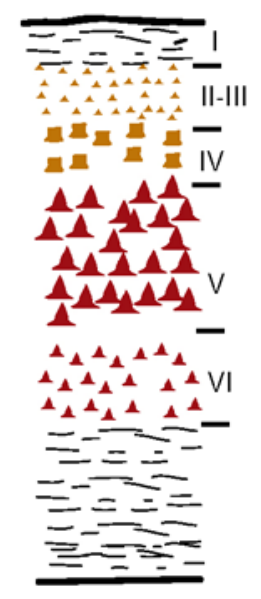

P0 cortex

Fig 1: Cortical layer formation in mice. Layering of the cortex during embryonic (E14.5) and postnatal (P0) stages is shown. CP, Cortical plate; SP, Subplate; IZ, intermediate zone; SVZ, Subventricular zone; VZ, Ventricular Zone and I-VI layers. (adapted from Zoltan \& Henry, 2005). 


\subsection{Signaling centers in patterning of cerebral cortex}

Regulation of gene expression during early development relies almost entirely on five pathways, namely Notch, transforming growth factor- $\beta$ (TGF- $\beta$ ), wingless/WNT, Sonic hedgehog (Shh) and receptor tyrosine kinase [Gerhart, 1999].

The cell surface receptor Notch has pleiotropic functions during development. Its signals seem to be involved in brain morphogenesis, neuronal progenitor maintenance, and neuronal migration. During gliogenesis, Notch promotes the differentiation of glial subtypes, with the exception of oligodendrocytes. In neurospheres Notch promotes differentiation of glia at the expense of neurons, followed by more specific differentiation into astrocytes, while repressing oligodendrocyte fate [Grandbarbe et al., 2003]. Thereby, Notch controls cell fate in a stepwise manner.

BMPs belong to the superfamily of TGF- $\beta$ and transduce their signal via Smad proteins. BMPs are involved in establishing dorsal and ventral cell fates in the embryonic mesoderm [Graff, 1997]. BMP-4 and OP-1 are both expressed in the epidermal ectoderm [Liem et al., 1995] and drive differentiation of dorsal cells in the nervous system. BMPs are important in dorso-ventral specification of cell fates and regulate differentiation of astrocytes from SVZ progenitors [Mehler et al., 1997].

Wnt signaling occurs through three major pathways; the canonical $/ \beta$-catenin, the planar cell polarity/JNK and the Ca2+/Protein kinase C pathways [Jones and Jomary, 2002]. 
Canonical Wnt signaling depends on $\beta$-catenin and is the best characterized of the three known pathways. Binding of Wnt ligand to Fzd receptor leads to the activation of Dishevelled, which ultimately leads to the stabilization of $\beta$-catenin via dephosphorylation. Regulation of canonical/ $\beta$-catenin Wnt signaling is achieved by cadherin-mediated cell adhesion. Cadherins are able to reduce the free cytoplasmic pool of $\beta$-catenin by sequestering it at the plasma membrane. Therefore, by regulating the levels of free $\beta$-catenin in the cytoplasm, the threshold for Wnt-activation may be dynamically modulated [Nelson and Nusse, 2004].

Non-canonical pathways are, by definition, independent of $\beta$-catenin. Binding of Wnt to Frizzled receptors in the absence of Low density lipoprotein receptor-related proteins (LRPs) activates Dishevelled, leading to activation of c-Jun NH2-terminal kinase (JNK) cascade through small GTP-binding proteins. Wnt signaling through Dishevelled, Rac and JNK controls dendritic development in cultured hippocampal cells [Rosso et al., 2005].

The $\mathrm{Ca} 2+$ Protein kinase $\mathrm{C}$ (PKC) Wnt pathway, like the PCP, is dependent on Dishevelled and independent of $\beta$-catenin and LRPs. Some Wnt signals can raise the levels of intracellular $\mathrm{Ca} 2+$ leading to the activation of $\mathrm{PKC}$ and $\mathrm{Ca} 2+-$ dependent calmodulin kinase II (CamKII).

Shh has a morphogen-like behaviour and has a pivotal role in generating a diverse array of neuronal subtypes that are required for the assembly and function of neuronal circuits [Briscoe and Ericson, 1999] especially within the vertebrate neural tube. Shh is initially 
expressed in the notochord, that lies below the ventral neural tube, but is rapidly induced within the ventral midline of the neural tube [Echelard et al., 1993]. Graded activity of Shh establishes distinct domains of homeobox gene expression along the dorsoventral axis of the neural tube [Briscoe et al., 2000]. Shh also has a direct role in regulating proliferation of neural progenitor cells. In the anterior neural tube, a number of structures like cerebellum, the neocortex and the tectum, depend on the mitogenic effect of Shh signaling [Dahmane et al., 2001].

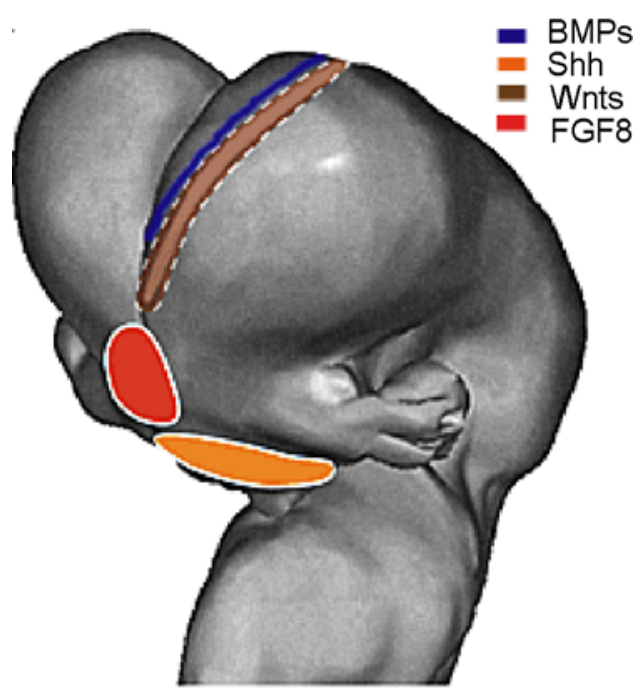

Fig 2: Signaling centers in the cerebral cortex. Medially, the dorsal roof plate produces BMPs; the cortical hem is a source of Wnts. Sonic hedgehog (Shh) is ventrally secreted from the prechordal mesoderm. FGF8 is mainly released from the anterior neural ridge. (adapted from Monuki \& Walsh, 2001). 


\subsection{Transcription factor Pax6 in cortical development}

\subsubsection{Structural and functional domains of Pax6}

Pax6 belongs to the Pax family of transcription factors and encodes a 422 amino acid protein that contains two highly conserved DNA-binding domains- a bipartite paired domain (PRD) and a homeodomain (HD), and a C-terminal region that functions in transcriptional activation [Bopp et al., 1986; Epstein et al., 1994b; Treisman et al., 1991; Walther and Gruss, 1991]. Mammalian Pax6 genes encode predominantly two forms of the Pax6 protein, Pax6 and Pax6(5a) [Carriere et al., 1993]. The 128 amino acid paired domain (PD) [Epstein et al., 1994a] can be separated structurally and functionally into two independent DNA binding subdomains, PAI and RED [Czerny et al., 1993; Epstein et al., 1994b]. Pax6(5a) contains a 14 amino acid insertion within the PAI domain forming a distinct paired domain, PD5a. This insertion destructs the DNA-binding capacity of the PAI subdomain, leaving the RED subdomain and the HD for DNA recognition [Epstein et al., 1994b]. The different DNA binding domains of Pax6 and Pax6(5a) can interact independently with DNA. Interaction between these domains is also crucial for the proper activation of a wide variety of target genes.

\subsubsection{Role of Pax6 in patterning of the brain}

Pax6 is involved in the dorsoventral specification of telencephalic progenitors. Expression of Pax6 is first detected in the neuroepithelium of the forebrain at around E8.0, and continues during neurogenesis. It shows a regionalized expression in the dorsal telencephalic primordium [Walther and Gruss, 1991], thus specifying the pallial- 
subpallial boundary (PSPB). Disruption of this boundary in the Pax6/Small eye mutant [Hill et al., 1991] leads to the invasion of cells from the subpallium into the neocortex [Chapouton et al., 1999]. It has also been shown that the molecular ventralization of pallial progenitors in Pax6 mutants leads to respecification of a subset of cortical glutamatergic neurons into subpallial GABAergic interneurons [Kroll and O'Leary, 2005]. Pax6 is expressed in the mitotically active ventricular zone and has previously been shown to control specification, regionalization and arealization of the cerebral cortex. In the wild type (wt) cortex, Pax6 is expressed in a high rostro- lateral to low caudo- medial gradient in apposition to the expression of transcription factors Emx1 and Emx2. Loss of Pax6 leads to the expansion of Emx2 expressing primary visual area, while loss of Emx2 leads to the expansion of caudal Pax6 domains containing somatosensory and motor areas [Bishop et al., 2002]. This was elucidated through studies using several cortical markers such as cad6, Cad8, Id2, RZRß, p75, EphA7 and ephrinA5 [Bishop et al., 2002].

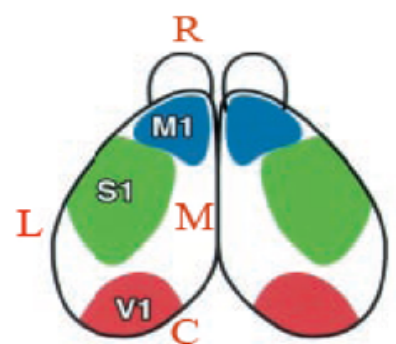

wildtype

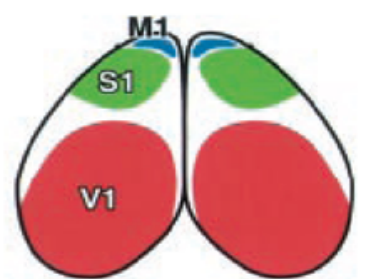

Sey/Sey

Fig 3: Arealization of mouse neocortex. The diagrams depict the disproportionate changes in area size and positioning in Pax6 mutants. The predicted organization is suggested by analysis of gene markers. In Pax6 mutants, rostro-lateral areas are reduced and the caudo-medial areas are expanded. The visual (V1), motor (M1), and somatosensory (S1) areas are shown. C, Caudal; L, lateral; M, medial; R, rostral; Sey, small eye mutant. (adapted from Bishop \& O’ Leary, 2002). 
In Pax6 mutants, dorsoventral patterning in the spinal cord is also lost [Ericson et al., 1997]. For example, the expression of Ngn2 in ventral spinal cord, which is also known to play a role in patterning, is missing in Pax6 mutants [Scardigli et al., 2001].

\subsubsection{Regulation of neurogenesis by Pax6}

Loss- and gain of function studies have showed that Pax6 is involved in the regulation of neurogenesis in the developing forebrain. Expression analysis using molecular markers of distinct layers of the neocortex have suggested that in Pax6 mutants, the upper cortical layers are missing [Tarabykin et al., 2001]. In the diencephalon and spinal cord too, certain subpopulations of neurons are lacking [Ericson et al., 1997; Mastick and Andrews, 2001].

\subsubsection{Pax6 in eye development}

Pax6 is a key regulator of vertebrate eye development and upon misexpression, is sufficient to induce ectopic eyes [Chow et al., 1999]. Mice strains carrying mutations in the Pax6 gene have a characteristic small eye [Hill et al., 1991], which is analogous to human aniridia. The predominant isoform of Pax6 expressed in the eye lacks exon 5a [Jaworski et al., 1997]. Pax6 plays multiple distinct roles in both lens [Ashery-Padan et al., 2000; Lang, 2004] and retinal [Marquardt et al., 2001] development, involving different interactions with other transcription factors. A single wild type Pax6 allele is not sufficient for normal eye development in humans and rodents, implying haploinsufficiency. 
Deletion of Pax6 affects the expression of a number of structural eye genes like keratins and crystallins. The sine oculis family gene Six3 [Ashery-Padan et al., 2000; Goudreau et al., 2002], and Maf [Sakai et al., 2001], a member of the v- Maf oncogene family that plays important roles in cellular differentiation, are known to be regulated by Pax6 during eye development [Blank and Andrews, 1997]. Mice heterozygous for Pax6 show small eye (Sey) phenotype whereas homozygote Pax6 mutants completely lack the entire eye structure [Hill et al., 1991].

\subsection{Cellular retinaldehyde-binding protein (CRALBP)}

Cellular retinaldehyde- binding protein (CRALBP) is a water-soluble retinoid-binding protein of 316 amino acids and belongs to the CRAL- Trio family of proteins. It is expressed in cornea, pineal gland, optic nerve, and abundantly in Muller cells and retinal pigment epithelial (RPE) cells [Bunt-Milam and Saari, 1983], where many of the reactions of the rod visual cycle take place. CRALBP is also expressed by oligodendrocytes of the optic nerve and brain [Saari et al., 1997]. It is a carrier of 11-cisretinol and 11-cis-retinaldehyde, that are known to function in vision [Saari et al., 1982]. It can interact with 11-cis retinoldehydrogenase in RPE resulting in the reduction of bound 11-cis-retinaldehyde [Saari and Bredberg, 1982].

Photoisomerization of 11-cis- to all-trans-retinal occurs in rod photoreceptor cells, whereas enzymatic isomerization of all-trans- to 11-cis-retinol occurs in adjacent retinal pigment epithelium (RPE). These two reactions occurring in different cellular 
compartments are linked into a cycle by the directed flow of retinoids through the intercellular matrix [Dowling, 1960; Wald, 1968; Zimmerman, 1974]. First, photoisomerization converts 11-cis-retinal to all-trans-retinal. All-trans-retinal is reduced to all-trans-retinol by reduced nicotinamide adenine dinucleotide phosphate (NADPH) and photoreceptor retinol dehydrogenase which is found within the rod photoreceptor outer segment. All-trans-retinol enters retinal pigment epithelium from rod photoreceptor cells, and is sequentially esterified by lecithin-retinol acyltransferase (LRAT). This ester is then converted to 11-cis-retinol by an isomerohydrolase, and oxidized to 11-cis-retinal by NAD (P) or with other short-chain dehydrogenase-reductases. 11- cis-retinal then diffuses back into the rod photoreceptor cell, where it regenerates rhodopsin and completes the visual cycle.

In CRALBP mutant mice, isomerization of all-trans- to 11-cis-retinol in the visual cycle is substantially impaired [Saari et al., 2001]. Mutations in the human gene encoding CRALBP cause autosomal recessive retinitis pigmentosa (arRP), a condition characterized by progressive photoreceptor degeneration and night blindness [Morimura et al., 1999]. It is also known to cause stationary night blindness, or other related conditions [Thompson and Gal, 2003], one characteristic of which is delayed dark adaptation [Burstedt et al., 2001]. 


\subsection{Transcription factor AP-2 gamma}

The Activating protein-2 (AP2) family of transcription factors consists of five members in humans and mice (AP-2 $\alpha, \beta, \gamma \delta$ and $\varepsilon$ ), that share a highly conserved helix-span-helix dimerization motif at the carboxyl terminal, and a less conserved proline and glutamine rich domain at the amino terminal. The embryonic lethal phenotype in mice lacking AP2 genes shows the importance of these genes during development [Moser et al., 1997a; Schorle et al., 1996; Werling and Schorle, 2002a; Zhang et al., 1996]. It has been shown that AP2 genes might play a role in promoting proliferation and repressing differentiation [Pfisterer et al., 2002].

AP-2 transcription factors are predominantly localized in the nucleus and have also been shown to interfere with signal transduction pathways downstream of Wnt by associating with APC (Adenomatous polyposis coli) tumor suppressor protein in the nucleus [ $\mathrm{Li}$ and Dashwood, 2004]. In mice, AP- $2 \alpha, \beta$, and $\gamma$ are coexpressed in neural-crest cells, the peripheral nervous system and extraembryonic trophoectoderm [Moser et al., 1997b; Zhao et al., 2003], and have been implicated in breast cancer [Jager et al., 2005; Turner et al., 1998]. The mouse AP $2 \gamma$ gene is expressed in the central and peripheral nervous system, ectoderm, face, limbs and mammary glands during mouse development, similar to the other AP2 family members [Chazaud et al., 1996; Mitchell et al., 1991; Moser et al., 1997b]. AP2 $\gamma$ is expressed in trophoblast cells as early as E3.5 of murine development. Its expression in all derivatives of the trophoblast lineage during chorioallantoic fusion [Sapin et al., 2000; Shi and Kellems, 1998] suggests that $A P-2 \gamma$ might play a role in regulating trophoblast gene expression programs. It is also essential 
for embryonic survival during early postimplantation period, and expression of AP2 $\gamma$ in the extra-embryonic membranes of AP2 $\gamma$ mutant embryos can rescue improper development [Auman et al., 2002]. AP2 $\gamma$ also regulates the expression of genes for human placental lactogen, chorionic gonadotropin- $\beta$ and adenosine deaminase (ADA) [Johnson and Jameson, 1999; Richardson et al., 2000; Shi and Kellems, 1998].

AP2 $\gamma$ was first identified in human breast cancer cell lines due to its ability to recognize critical regulatory element within the erbB2 promoter [Bosher et al., 1996]. Later it was also found to interact with regulatory elements associated with the estrogen receptor gene, involved in oncogenesis [McPherson et al., 1997]. Moreover, tumor progression in a murine breast-cancer model is enhanced after transgenic overexpression of AP2 $\gamma$ [Jager et al., 2005]. These data show a direct role of AP $2 \gamma$ in regulating expression of molecules associated with cell proliferation, especially in breast cancer.

Heterozygous AP2 $\gamma$ mutant mice are viable and display reduced body size at birth. In homozygous mutants, proliferation rate is reduced in the extraembryonic ectoderm eventually leading to a failure in labyrinth layer formation. The embryo is deprived of nutrients resulting in growth retardation and eventual death [Werling and Schorle, 2002a]. 


\section{Materials and Methods}

\subsection{Animals}

Mouse strains carrying floxed alleles for exon 5 of AP2 gamma [Werling and Schorle, 2002b] were crossed with mice that express Cre recombinase under the Emx $1^{\text {IRESCre }}$ promoter [Gorski et al., 2002]. LoxP sites that flank exon 5 of AP2 gamma gene are recognized by the Cre- recombinase enzyme that mediates a loop out reaction of the $5^{\text {th }}$ exon resulting in a truncated and nonfunctional protein. Heterozygous mice (AP2 $\gamma$ flox/cre) were crossed to obtain conditional knockout mutants for AP2 $\gamma$.

CRALBP knock out mice in which $\mathrm{Neo}^{\mathrm{r}}$ was inserted into exon 3 of the coding sequence [Saari et al., 2001] was used for the project.

\subsection{Molecular biology procedures}

\subsection{Mouse genotyping}

\subsubsection{DNA Isolation}

Tail or yolk sac (from young mice or embryo's respectively) was incubated in $0.5 \mathrm{ml}$ PKlysis buffer (100mM Tris- $\mathrm{HCl} \mathrm{pH} 8.5,5 \mathrm{mM}$ EDTA, $200 \mathrm{mM} \mathrm{NaCl}, 0.2 \% \mathrm{SDS}, 100 \mu \mathrm{g} / \mathrm{ml}$ Proteinase $\mathrm{K}$ ), shaking at $55^{\circ} \mathrm{C}$ overnight. After a 10 min centrifugation at $13,000 \mathrm{rpm}$, the DNA in the supernatant was precipitated by the addition of isopropanol to a final concentration of $50 \%$. Genomic DNA was collected by centrifugation, washed twice in $80 \%$ ethanol and resuspended in water at $40^{\circ} \mathrm{C}$ for $1 \mathrm{hr}$. 


\subsubsection{Polymerase chain reaction (PCR)}

All PCR reactions were carried out in an end volume of $20 \mu$ that contained:

10x Buffer (Genecraft) $\quad 2 \mu 1$

10mM dNTP's (Invitrogen) $\quad 0.4 \mu \mathrm{l}(20 \mathrm{pmol} / \mathrm{ml})$

Primer1/Primer2 (IBA) $\quad 0.8 \mu l(40 \mathrm{pmol} / \mathrm{ml})$ each

TAQ polymerase (Genecraft) $\quad 0.4 \mu 1$ (0.5 units)

Template DNA $\quad 1 \mu \mathrm{l}$

$\mathrm{dH} 2 \mathrm{O} \quad 13 \mu \mathrm{l}$

To detect wt and floxed AP2 $\gamma$ alleles, mice were genotyped using specific primers;

A forward primer against exon 5

5'- CAATTTTGTCCAACTTCTCCCTCAA- 3'

and a reverse primer that recognizes intron 4

5'- AACAGGTTATCATTTGGTTGGGATT- 3' were used.

In wt mice, the PCR generated a fragment of $\sim 300 \mathrm{bp}$ whereas floxed alleles generated a fragment of $\sim 340 \mathrm{bp}$ [Werling and Schorle, 2002b].

To identify Cre recombinase gene, a $500 \mathrm{bp}$ fragment was amplified $\left(94^{\circ} \mathrm{C} 10 \mathrm{sec}, 55^{\circ} \mathrm{C}\right.$ $30 \mathrm{sec}, 72^{\circ} \mathrm{C} 40 \mathrm{sec} ; 30$ cycles) using the following primers:

5'-TCGATGCAACGAGTGATGAG- 3' (forward)

5'-TTCGGCTATACGTAACAGGG- 3' (reverse). 
To identify wt and CRALBP knockout mice, genotyping was done using the following primers [Saari et al., 2001]: For wt exon 3,

5' -TTA GAC TCA CAG GGG CCA ACA- 3' (forward)

5' -ATG ATC CTT GGT TGT GAG CTG CTC- 3' (reverse);

For neomycin ${ }^{\mathrm{r}}$,

5'-ATT TTG AAT GGA AGG ATT GGA GCT A-3 (forward)

5-ATG ATC CTT GGT TGT GAG CTG CTC-3 (reverse)

To detect putative Pax6 binding sites on AP2 $\gamma$ and CRALBP promoter, Chromatin immunoprecipitation assay (ChIP) was performed. As a positive control, the following primers were used against Pax6 promoter region ( $\sim 300 \mathrm{bp})$

5'- CCCACCCTCAGGCTTCCA- 3' (forward)

5'-CTCCCGAGCCTGCCCATT- 3' (reverse).

Five primer pairs flanking putative Pax6 consensus sequences upstream of exon1 of AP2 $\gamma$ were designed as follows:

1. -623 to -985 bp upstream (362 bp fragment)

5'-GGACAGGTTGAGCTAGAGTT -3' (forward)

5'-CCGGTGTAGAGAAGGAATGA -3' (reverse);

2. -1855 to $-2188 \mathrm{bp}$ upstream ( $380 \mathrm{bp}$ fragment)

5'-GAGTTGAGACACCCTGGAAT-3' (forward)

5'-GGGGACCCGAACGCCTTAAT-3' (reverse);

3. -3329 to -3644 bp upstream ( 315 bp fragment) 
5'-TGAGGAAAGGCGAATGCAGA-3' (forward)

5'-TGGAATTAGCGGGAGAAGAG-3' (reverse);

4. -5405 to $-5686 \mathrm{bp}$ upstream (281 bp fragment)

5'-CTTCTGTCTTTAACCCCTGC-3' (forward)

5'-TACTAGGCTTCCACACACCT-3' (reverse);

5. -6839 to $-7187 \mathrm{bp}$ upstream (348 bp fragment)

5'-TCCTCGGACTCGATTGTACA-3' (forward)

5'-GTCACTTCTGGGGCAAAGAT-3' (reverse);

Five primer pairs flanking putative Pax6 consensus sequences upstream of exon1 of CRALBP gene were designed as follows:

1. -2009 to $-1671 \mathrm{bp}$ upstream (338 bp fragment)

5'-GACACACTAATCCCAGCTTG- 3' (forward)

5'-GAGTATTTGATCACCTGCCAT- 3' (reverse);

2. -2998 to -2727 bp upstream (271 bp fragment)

5'-TGTGGCTGGATTTCAGAGAA3' (forward)

5' -CAGGCTAAGGGAATGCATC- 3' (reverse);

3. -3453 to -3128 bp upstream (325 bp fragment)

5' -AGGTAGGTGGCCAACAGTA- 3' (forward)

5' -TATGCCCAAAGAACCTCCCT- 3' (reverse);

4. -4660 to -4336 bp upstream (324 bp fragment)

5'-TCTGATACCTCTGCACCAG 3' (forward)

5'-CTTTCTTGACTGCGATTTCCC3' (reverse); 
5. -5713 to $-5441 \mathrm{bp}$ upstream (272 bp fragment)

5'-TGCTAAGGTGTTAACAGGCC- 3' (forward)

5' -CTGGCACTGGGATTACAAATG- 3' (reverse);

PCR conditions were as follows: $2 \mathrm{~min}$ at $94{ }^{\circ} \mathrm{C}$ followed by 34 cycles of $30 \mathrm{~s}$ at $94{ }^{\circ} \mathrm{C}$, $30 \mathrm{~s}$ at $60{ }^{\circ} \mathrm{C}, 30 \mathrm{~s}$ at $72{ }^{\circ} \mathrm{C}$.

All PCR products were separated by $1.5 \%$ agarose gel electrophoresis at $5 \mathrm{~V} / \mathrm{cm}$ (chamber length). Agarose gels were prepared in TAE buffer (40mMTris- acetate, 1mMEDTA, pH 8) containing $0.5 \mu \mathrm{g} / \mathrm{ml}$ ethidium bromide (Fulka) and visualized under ultra violet light. DNA was loaded using OrangeG buffer, and 100 bp or $1 \mathrm{~kb}$ plus DNA markers (Invitrogen) were used at a concentration of $50 \mathrm{ng} / \mu 1$.

\subsection{Preparation of Probes for In situ hybridization}

\subsubsection{Transformation}

Amplification of the desired cDNA plasmid was carried out using competent cells

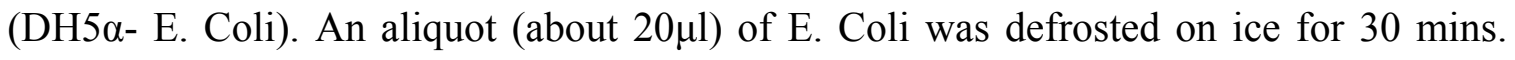
Plasmid of interest $(1 \mu \mathrm{l})$ was added to the bacterial cells and incubated on ice for 10 mins. Cells were transformed by heat shock $\left(42^{\circ} \mathrm{C} ., 30 \mathrm{sec}\right)$ and placed on ice for 5 mins. They were then incubated in LB medium for $1 \mathrm{hr}$ with slight agitation and finally plated on selective LB- agar plates containing appropriate antibiotics (penicillin $100 \mathrm{mg} / \mathrm{ml}$ ). Such plates were incubated at $37^{\circ} \mathrm{C}$ overnight for the growth of individual colonies. 


\subsubsection{Plasmid isolation (mini prep)}

Individual colonies developed on agar plates were inoculated in $3 \mathrm{ml} \mathrm{LB}$ medium containing appropriate antibiotics for $10-16 \mathrm{hrs}$ at $37^{\circ} \mathrm{C}, 220 \mathrm{rpm}$. The bacterial pellet was obtained by centrifugation (10 mins, 3000rpm). Plasmid isolation was performed using a Macherey- Nagel NucleoSpin ${ }^{\mathrm{TM}}$ plasmid Kit, according to the manufacturer's specifications.

\subsubsection{Plasmid linearization and purification}

Purified plasmids were linearized using specific restriction enzymes (New England biolabs), according to the orientation of the cDNA fragment and the characteristics of the vector. Plasmid DNA was diluted in $\mathrm{dH} 2 \mathrm{O}$ to a concentration of $50 \mathrm{ng} / \mu \mathrm{l}$ and the following components were added:

1:10 of 10x Buffer, $1-5 \mu 1 / \mathrm{ml}$ of restriction enzyme and 1:100 of 100x BSA (if required). Reactions were normally at $37^{\circ} \mathrm{C}$ for few hours or even overnight until complete restriction, as verified by gel electrophoresis.

To purify DNA from proteins, an equal volume of Tris- saturated phenolchloroform/isoamyl alcohol $\mathrm{pH} 8$ (Invitrogen) was added to the complete reaction mixture. This mixture was then vortexed gently and centrifuged (10 min, 13000rpm). The upper aqueous phase was transferred to a new tube and 0.1 volume of $3 \mathrm{M}$ sodium acetate (pH5.5) was added. After vortexing, DNA was precipitated with 3 volumes of $100 \%$ ethanol for $1 \mathrm{hr}$ at $-20^{\circ} \mathrm{C}$, washed twice in $70 \%$ ethanol and resuspended in $\mathrm{H} 2 \mathrm{O}$ to a final concentration of $0.1-1 \mu \mathrm{g} / \mu \mathrm{l}$. 


\subsubsection{Synthesis of radioactive riboprobes}

In vitro transcription of the linearized cDNA was carried out by incubating at $37^{\circ} \mathrm{C}$ for $1.5 \mathrm{hrs}$ with the following reagents:

Linearized DNA $(>0.25 \mu \mathrm{g} / \mu \mathrm{l})$

Transcription Buffer 10x (Boehringer)

-U dNTPs (Boehringer)

RNase inhibitor (Promega)

T3/T7/SP6 RNA polymerase (Promega)

[a]35 S- UTP (Amersham)

DEPC- $\mathrm{H} 2 \mathrm{O}$
$1-3 \mu 1(0.5-1 \mu \mathrm{g})$

$1 \mu 1$

$1 \mu 1$

$0.5 \mu \mathrm{l}(1 \mathrm{U} / \mu \mathrm{l})$

$0.5 \mu \mathrm{l}(0.5 \mathrm{U} / \mu \mathrm{l})$

$2 \mu \mathrm{l}(10 \mathrm{mCi} / \mathrm{ml})$

up to $10 \mu 1$ 
Riboprobes bearing a sequence complementary to the mRNA of interest (antisense) were synthesized using the following cDNA templates:

$\begin{array}{llllll}\text { cDNA } & \text { Size }(\mathrm{bp}) & \text { Vector } & \text { Enzyme } & \text { Pol } & \text { Provider } \\ \text { Cad8 } & 400 & \text { pGEM-Teasy } & \text { SpeI } & \text { T7 } & \text { Lab stock } \\ \text { Cralbp } & 310 & \text { pGEM-T } & \text { SpeI } & \text { T7 } & \text { Lab stock } \\ \text { Cux2 } & 530 & \text { pGEM-T } & \text { SpeI } & \text { T7 } & \text { Lab stock } \\ \text { Er81 } & 300 & \text { pGEM-Teasy } & \text { SacII } & \text { SP6 } & \text { Lab stock } \\ \text { Id2 } & 350 & \text { pGEM-Teasy } & \text { SpeI } & \text { T7 } & \text { Lab stock } \\ \text { Lmo4 } & 600 & \text { pGEM } & \text { SpeI } & \text { T7 } & \text { Lab stock } \\ \text { Pax6 } & 260 & \text { pBluescriptKS }+ & \text { EcoRI } & \text { T3 } & \text { P. Gruss } \\ \text { Svet1 } & 900 & \text { pBluescript } & \text { XhoI } & \text { T7 } & \text { P. Gruss }\end{array}$

\subsubsection{In situ Hybridization}

Dewaxing of paraffin embedded tissue (sectioned cortex and whole embryo) was done using histoclear (twice for 10 mins). The tissue was rehydrated in a series of ethanol dilutions $(100 \%, 100 \%, 95 \%, 90 \%, 80 \%, 70 \%, 50 \%, 30 \%$, for 2 mins each) and rinsed in saline $(0.86 \% \mathrm{NaCl}$ in DEPC autoclaved water) and PBS- DEPC. The sections were then fixed in cold 4\% PFA/PBS and washed twice in PBS- DEPC for 5 mins. The sections were then Proteinase K treated ( 50mMTris- HCl; 5mM EDTA; $20 \mu \mathrm{g} / \mathrm{ml}$ Proteinase K) followed by a PBS- DEPC wash step. These sections were treated with freshly prepared acetylation buffer $(0.1 \mathrm{M}$ triethanolamine; $0.05 \mathrm{M}$ acetic anhydride in DEPC- H2O), twice for 15 mins and washed in PBS- DEPC followed by dehydrating ethanol wash steps. 
Hybridization buffer was used for diluting the radioactive RNA probe:

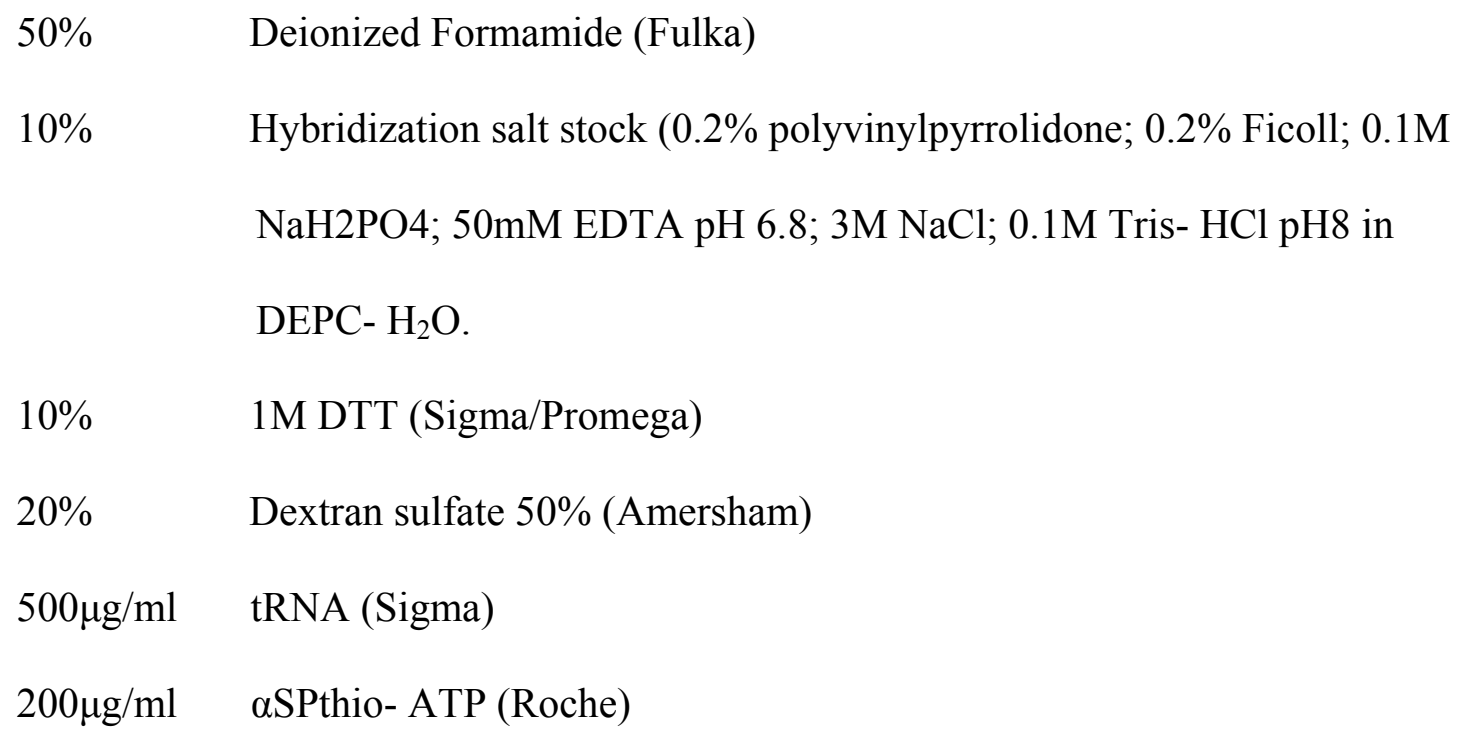

Denaturation of the diluted radiolabelled RNA probes was done at $80 \%$ for 2 mins and placed on ice for 5 mins. About 12- $18 \mu$ of the diluted probe was applied on each section and covered with $15 \times 20 \mathrm{~mm}$ coverslips that were previously siliconized with SurfaSil ${ }^{\mathrm{TM}}$, according to the manufacturer's instructions. Sections were allowed to hybridize with the probe at $55^{\circ} \mathrm{C}$ in a completely sealed humid chamber containing $50 \%$ formamide in $2 \mathrm{xSSC}$.

Hybridized sections were transferred to $2 \mathrm{xSSC}$ at $55^{\circ} \mathrm{C}$ and coverslips were removed with gentle agitation for about 5- 10 mins. sections were then washed in $50 \%$ Formamide $/ 2 \mathrm{xSSC}$ at $75^{\circ} \mathrm{C}$, then at $65^{\circ} \mathrm{C}$ (both in a shaking water bath). This wash step was again carried out in a fresh aliquot of the same solution for $30 \mathrm{~min}-2 \mathrm{hr}$ at $37^{\circ} \mathrm{C}$ with slight agitation. Sections were then incubated twice in NTE buffer $(0.5 \mathrm{M} \mathrm{NaCl} ; 10 \mathrm{mM}$ Tris- $\mathrm{HCl}$; 5mM EDTA pH8) for 5 and 15 mins. The unbound radiolabelled RNA probe 
was digested with $20 \mu \mathrm{g} / \mathrm{ml}$ RNase A (Boehringer) in NTE buffer at $37^{\circ} \mathrm{C}$ for 30 mins. Sections were then incubated at $37^{\circ} \mathrm{C}$ in NTE buffer (shaking for 15 mins) to wash out the RNase. They were washed in preheated $50 \%$ Formaminde $/ 2 \mathrm{xSSC}$ at $65^{\circ} \mathrm{C}$ then at $37^{\circ} \mathrm{C}$ for 30 mins each. To decrease salt concentration, sections were first washed in $2 \mathrm{xSSC}$ and then in $0.1 \mathrm{xSSC}$ for 15 mins each. They were finally dehydrated with the ethanol wash steps and allowed to dry. A preview of the signal was obtained by exposing the sections to Biomax X- ray film (Kodak) overnight.

Autoradiography with the hybridized sections was performed in complete darkness by embedding the slides in NTB- 2 emulsion (Kodak) pre- warmed at $42^{\circ} \mathrm{C}$. Sections were allowed to dry and exposed overnight at RT then transferred to $4^{\circ} \mathrm{C}$ for 5- 10 days depending on the strength of the signal obtained on the X- ray film. After exposition, the emulsion was developed in total darkness by dipping in cold 16\% (w/v) Kodak D- 19 developer solution for 4 mins, washed in 1\% (v/v) acetic acid for 1 min and fixed in 30\% (w/v) sodium thiosulfate (Sigma) for 3 mins. Slides were finally washed several times in water and counterstained in a solution containing $4 \%$ Giemsa stock $(0.85 \%$ Giemsa; $50 \%$ Glycerol; 50\% Methanol) and 2\% 0.2Msodium phosphate buffer (pH6). The excess of stain was washed out in running tap water. These sections were air- dried and mounted with Eukitt ${ }^{\circledR}$. 


\subsection{Chromatin Immunoprecipitation (ChIP) Assay}

Mouse embryonic cortex (E14.5 or E 15.5) was used as a tissue source of chromatin. Cortex tissues were homogenized in $1 \mathrm{x}$ phosphate-buffered saline $(10 \mathrm{ml}$ for $10-14$ hemispheres of cortex tissue) with protease inhibitors (Roche Applied Science). Proteins were cross-linked in $1 \%$ formaldehyde for $10 \mathrm{~min}$ at $37 \mathrm{C}$ in a water bath incubator. Cross-linking was terminated with three washes in 1x phosphate-buffered saline. Samples were then processed using a ChIP assay kit, essentially as described by the manufacturer (Upstate biotechnology, Lake Placid, NY). In brief, the cells were lysed in SDS lysis buffer with protease inhibitors, then sonicated using a waterbath sonicator, super RK 103H from Schütt labortechnik (Goettingen, Germany) to shear DNA to fragments with a length of 100-1000 bp. To reduce nonspecific background, the cell lysates were precleared by incubation with salmon sperm DNA/protein A-agarose slurry. The agarose beads were pretreated with $2 \%$ BSA before the preclearing step as suggested by the company. Supernatants from the preclearing step were incubated with (1: 500) rabbit anti-Pax6 polyclonal IgG (Covance), at $4{ }^{\circ} \mathrm{C}$ overnight. Cortex from Pax6 mutant mice were used as a negative control. Chromatin-antibody complexes were precipitated by incubation with Protein A-agarose beads. Chromatin was eluted from the beads after washes in several buffers provided with the kit. The DNA-protein cross-links in all samples were reversed by incubation for $4 \mathrm{~h}$ at $65{ }^{\circ} \mathrm{C}$ followed by incubation with proteinase $\mathrm{K}$ for $1 \mathrm{~h}$ at $45{ }^{\circ} \mathrm{C}$. DNA was isolated by phenol/chloroform extraction and ethanol precipitation. PCR was performed with primers that recognize known and putative Pax6 binding sites (refer to ChIP primers in PCR). 


\subsection{Immunohistochemistry}

Immunohistochemistry was performed on $10 \mu \mathrm{M}$ thick cryosections of E14.5 wild-type and pax6 mutant brains. Freshly isolated brains were fixed in $4 \%$ PFA for $2-4 \mathrm{hrs}$ at $4{ }^{\circ} \mathrm{C}$, soaked in 30\% sucrose overnight and cryopreserved in tissue-tek (Sakura Finetek Zoeterwoude, NL). Immunohistochemistry was carried out with rabbit anti-CRALBP (kindly provided by Prof. John Saari, University of Washington, Seattle; 1:500) and mouse monoclonal Pax6 (Developmental Studies Hybridoma Bank, Iowa; 1:100) antibodies. Sections were blocked in 1\% BSA and $0.5 \%$ Tween in PBS for $1 \mathrm{hr}$, rinsed in PBS and incubated for 2 hrs with primary antibodies at RT. Primary antibodies were washed in PBS and detected using fluorescent secondary antibody (1:1000) for $1 \mathrm{hr}$. Sections were rinsed in PBS and visualized using a fluorescent microscope after mounting with Dako.

\subsection{Plasmid constructs and luciferase reporter assay}

Chinese hamster ovarian $(\mathrm{CHO})$ cells were cultured in neurobasal medium in 10\% FCS and $1 \%$ Pen/Strep. These cells were plated in a 96 well plate at a density of 30,000 cells /well and 12 hrs later, they were transfected with Pax6 cDNA plasmid [Walther and Gruss, 1991] and luciferase cDNA plasmid under the CRALBP promoter as previously described [Intres et al., 1994; Kennedy et al., 1998]. Lipofectamin was used to increase the efficiency of transfection. $24 \mathrm{hrs}$ after transfection, cells were washed twice in cold PBS and lysed using lysis buffer. The firefly and Renilla luciferase activities were measured using a dual luciferase assay system kit (Promega UK) and a Microlumat Plus 
LB 96V luminometer (Berthold Technologies GmbH \& Co. KG, Bad Wildbag, Germany).

\subsection{Histology}

Freshly isolated brains were dehydrated with a series of ethanol wash steps $(30 \%, 50 \%$, $70 \%, 80 \%, 90 \%, 95 \%$ and $100 \%$ ) for atleast $2 \mathrm{hrs}$ each, transferred to toluol for $6 \mathrm{hrs}$, soaked in fresh paraplast, twice, overnight and then embedded.

\subsection{Image acquisition}

Bright and dark field images were obtained with a light microscope (Olympus). To obtain fluorescent images, a Zeiss Confocal microscope was used (Zeiss LSM 510 META). Images obtained were edited using Adobe Photoshop CS2 ${ }^{+}$. 


\section{Aim of the project}

We investigated the regulatory role of transcription factor Pax6 in cortical development. It is well known that Pax6 regulates cell proliferation, differentiation and migration in various tissues during development. In this study, we focus on CRALBP and AP2 $\gamma$, two genes that were downregulated in Pax6 mutants as seen through microarray based comparison of gene expression.

CRALBP is a carrier of 11-cis retinol, a derivative of vitamin A. Knowing the importance of vitamin A in neuronal development; we wanted to investigate if Pax6 mediates some of its functions through CRALBP. We wanted to study the expression of CRALBP in various tissues and analyzed the cortical phenotype in CRALBP mutants.

Loss of Pax6 has been show to abolish, downregulate and misexpress many cortical markers. We wanted to conduct expression analysis in AP2 $\gamma$ mutants and investigate if Pax6 regulates some of its target genes through AP2 $\gamma$. Transcription factor AP2 $\gamma$ is known to play roles in proliferation and repress differentiation. We wanted to study possible alterations in proliferation domains and lamination problems in AP2 $\gamma$ mutants. 


\section{Results}

To identify potential target genes activated by the transcription factor Pax6, we performed a microarray analysis with E $14.5 \mathrm{wt}$ and Pax6 mutant cortex and found several genes that were downregulated in Pax6 mutants (data not shown). Two of the genes that were downregulated in Pax6 mutants encode for AP2 $\gamma$ and CRALBP proteins. CRALBP is a carrier protein involved in the transport of 11- cis retinal and has a role in the visual cycle. AP2 $\gamma$ belongs to AP2 family of transcription factors that play important roles in development. In wt cortex, during embryonic development, both genes were expressed in the VZ; this proliferative layer of the cortex also shows strong Pax6 expression.

\subsection{Analysis of CRALBP function in the cortex}

We investigated the role of CRALBP, a 11- cis retinal binding protein, in cortical development. CRALBP was very strongly downregulated in Pax6 mutants as seen through microarray analysis. CRALBP is known to play an important role as a carrier protein for 11- cis retinal in the visual cycle of the eye [Saari et al., 2001]. The expression of CRALBP in the cortex at earlier stages of development indicated that it could have a role in coticogenesis. This motivated us to investigate the role of CRALBP in the cortex. Since, Pax6 is a pleiotropic player in development it could mediate some of its functions through CRALBP. We wanted to find out whether CRALBP is a direct downstream target of Pax6. 


\subsubsection{Pax6 and CRALBP are coexpressed in several regions of the CNS}

To study mRNA expression of CRALBP in wt and Pax6 mutants we performed in situ hybridization with radiolabelled antisense-RNA probes. The expression of CRALBP during embryonic stages (E14.5) in wt brain was almost identical to the expression of Pax6. CRALBP was expressed in the neocortical VZ, cortical hem and in the hypothalamus (Fig: 4c). In Pax6 mutant cortex the expression of CRALBP was abolished in all these regions (Fig: 4d). Since Pax6 is also expressed in the spinal cord, we investigated the expression of CRALBP in the spinal cord using in situ hybridization. In wt spinal cord, Pax6 and CRALBP are expressed in the VZ (Fig: 5b and c) of the spinal cord. No expression of CRALBP was detected in the spinal cord in Pax6 mutants (Fig: $5 d)$.

Next, we addressed the question of whether Pax6 and CRALBP are expressed in the same cells. To study protein expression, a double immunohistochemistry (IHC) was performed on E14.5 wt and Pax6 mutant cryosections. In wt brain, CRALBP was expressed in all Pax6 expressing regions. These regions included cortical hem, pallialsub-pallial boundary (PSPB) of the cortex (Fig: 6) and regions around the third ventricle in the thalamus (Fig: 7). In all these regions CRALBP showed sharp boundaries of expression which coincided with those of Pax6. We did not find any CRALBP expressing regions that lack Pax6 expression. However, in the neocortex as opposed to Pax6, expression of CRALBP was not only detected in the ventricular zone but also in the cortical plate (Fig: 6e). In Pax6 mutant brains, we did not find any expression of CRALBP protein (data not shown). The complete abolishment of CRALBP expression 
(mRNA and protein) in Pax6 mutants suggested that $C R A L B P$ could be a direct downstream target of Pax6.
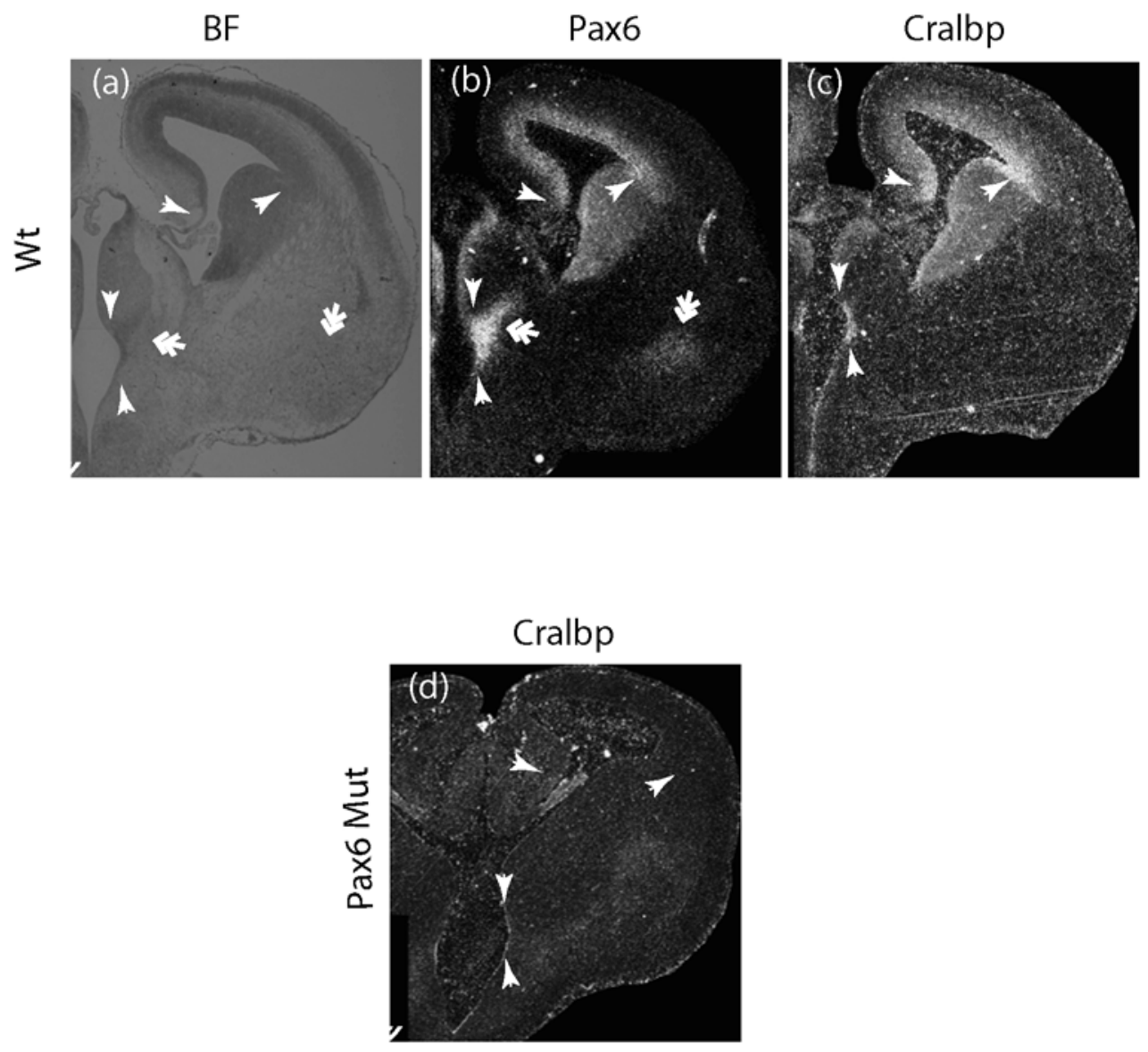

Fig 4: In situ hybridization with Pax6 and CRALBP probes in Wt and Pax6 mutant cortex. Pax6 and CRALBP are expressed in the cortical hem, neocortical VZ, PSPB, and around the third ventricle as shown by single arrowheads (b and c). Pax6, and not CRALBP, is also expressed in some postmitotic areas as shown by double arrow heads (b). In Pax6 mutants, expression of CRALBP is completely abolished (d). 

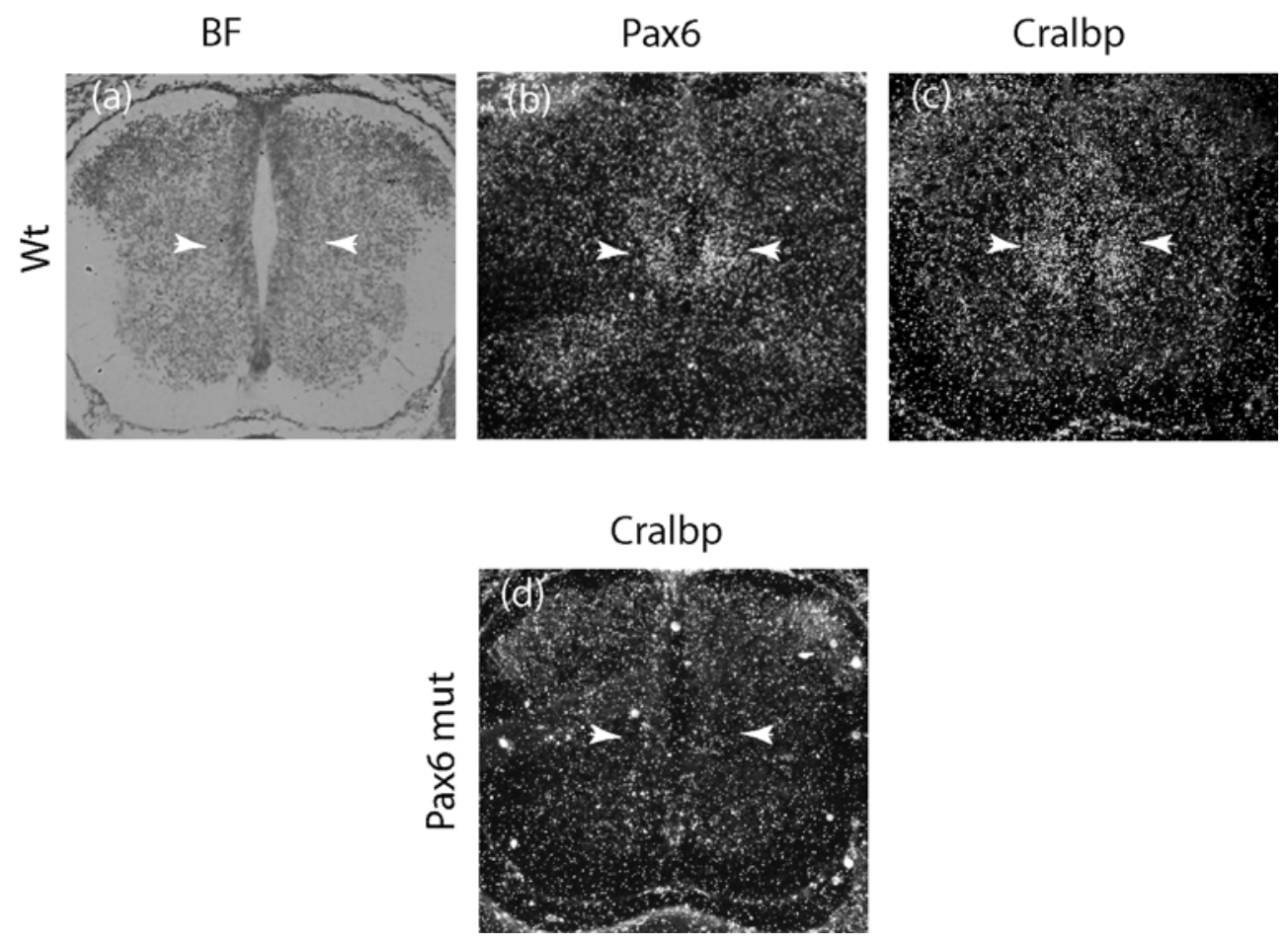

Fig 5: In situ hybridization with Pax6 and CRALBP probes in the spinal cord of Wt and Pax6 mutant. Pax6 and CRALBP are expressed in the VZ of spinal cord in wt (b and c) as indicated by arrowheads. In Pax6 mutants, expression of CRALBP is completely abolished (d). The corresponding bright field image is also shown (a). 


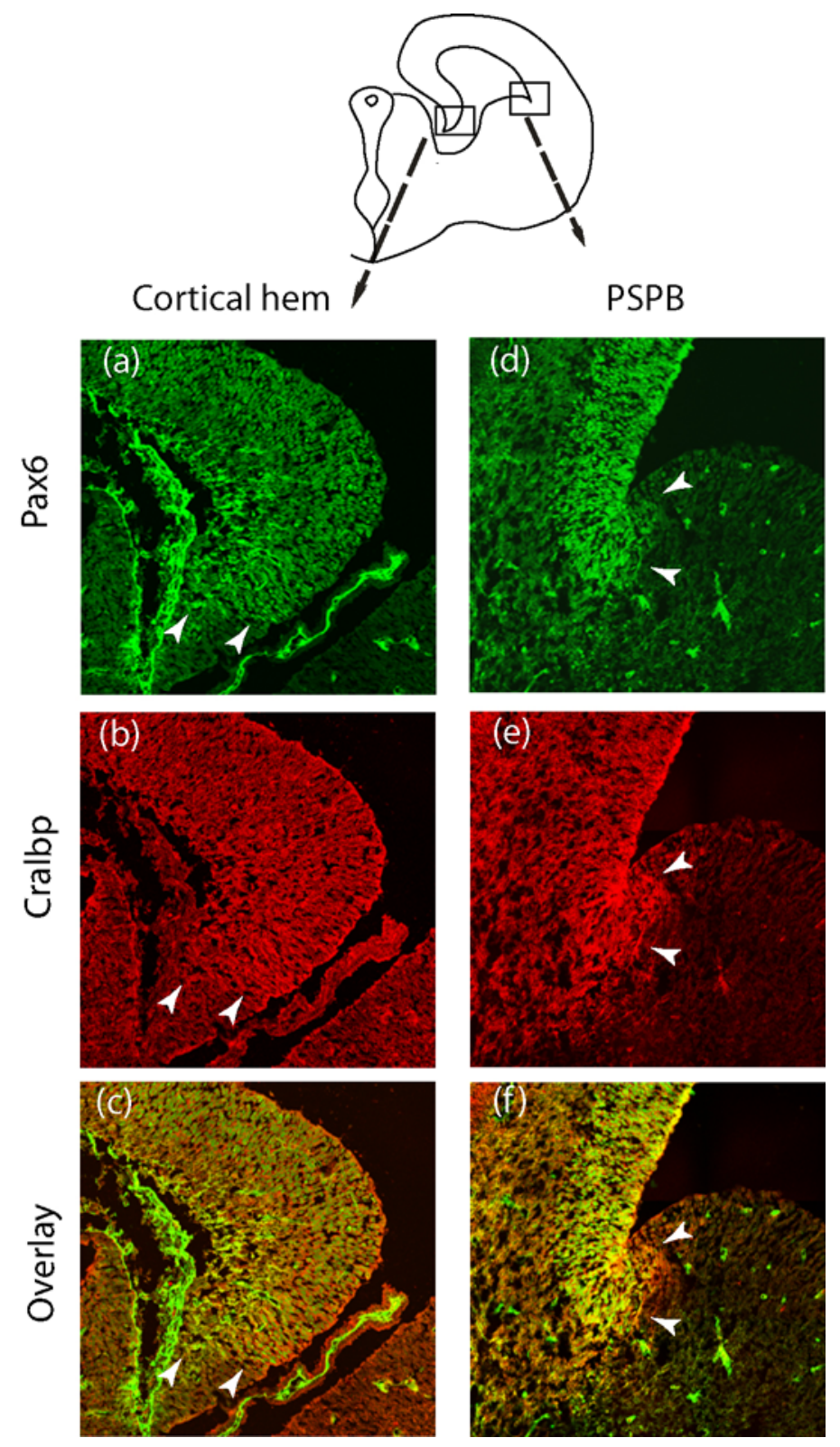

Fig 6: Comparison of Pax6 and CRALBP expression in the cortex by Immunohistochemistry. Pax6 and CRALBP share similar borders of expression in the cortical hem ( $a, b$ and $c$ ) and the pallial- subpallial boundary (PSPB; d, e and f). Both proteins have common expression domains (as indicated by arrows). 

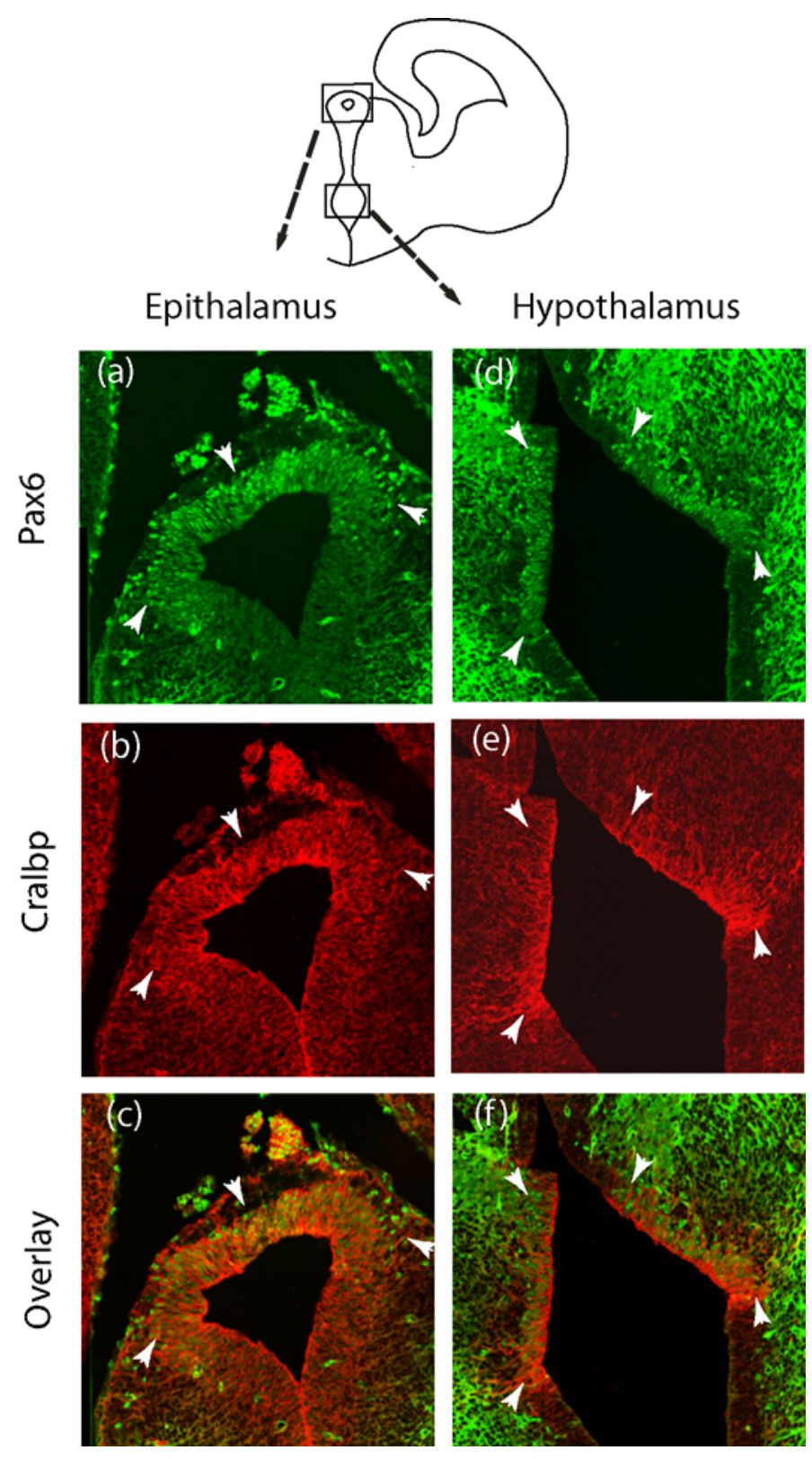

Fig 7: Comparison of Pax6 and CRALBP expression in the thalamus by Immunohistochemistry. Pax6 and CRALBP share similar boundaries of expression around the third ventricle in the epithalamus ( $a, b$ and $c$ ) and the hypothalamus (d, e and $f$ ). Both proteins have common expression domains (as indicated by arrows). 


\subsubsection{Mutually exclusive expression domains of Pax6 and CRALBP in the eye}

Pax6 is a key regulator of vertebrate eye development and upon misexpression is sufficient to induce ectopic eyes [Chow et al., 1999]. Pax6 mutants lack entire eye structure. These findings led to the proposal that Pax6 could be an 'eye selector gene'. CRALBP also plays an important role as a carrier protein in the eye. Since both proteins are known to play important roles in the eye, we wanted to investigate the expression patterns of Pax6 and CRALBP through IHC. Our experiments have shown that Pax6 is expressed in the neuroretina (NR) whereas CRALBP is expressed in the retinal pigment epithelium (RPE) that surrounds the neuroretina (Fig: 8a and b). Our results indicate that Pax6 and CRALBP are not co-localized in the eye (Fig: 8c). We could not investigate the expression of CRALBP in Pax6 mutants since Pax6 mutants are devoid of eyes [Hill et al., 1991].
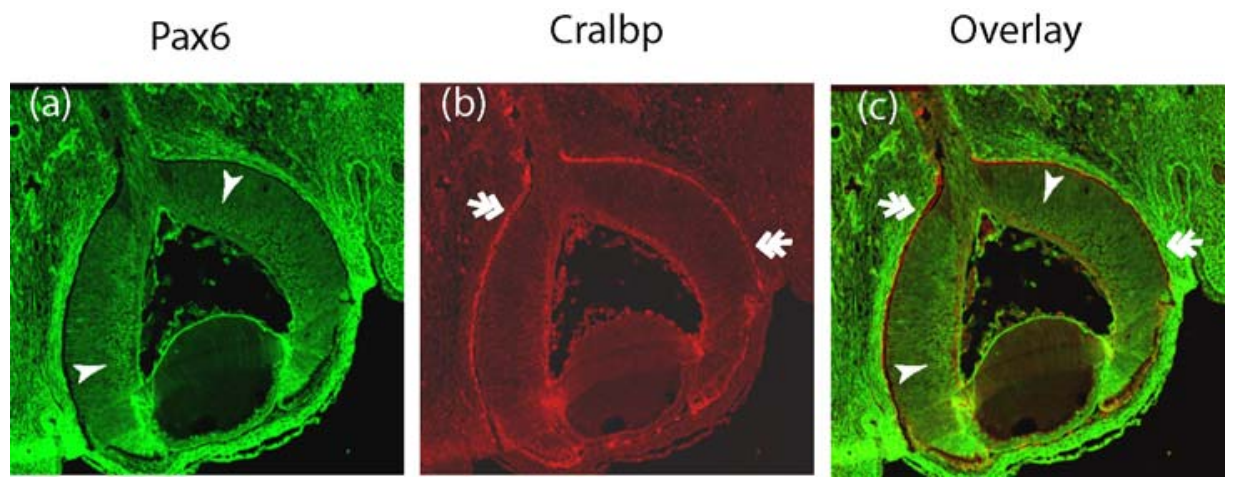

Fig 8: Comparison of Pax6 and CRALBP expression in the eye. Pax6 and CRALBP are expressed in different regions of the eye. Pax6 is expressed in the neuroretina (a) and CRALBP is expressed in the retinal pigment epithelium (b). They do not share overlapping domains of expression (c). 


\subsubsection{Chromatin immunoprecipitation assay (ChIP) reveals Pax6 binding sites on}

\section{CRALBP promoter.}

Our expression data from in situ hybridization and IHC (Fig: 4, 5, 6 and 7) suggested that Pax6 directly regulates the expression of CRALBP. Since putative Pax6 binding sites are known [Epstein et al., 1994a; Morgan, 2004; Sander et al., 1997], we inspected the 5' upstream region of exon1 of the mouse $C R A L B P$ gene. We were able to identify 6 putative Pax6 binding sites within $6 \mathrm{~kb}$ upstream. The consensus sequence "CACGTG" [Morgan, 2004] was located at $5.7 \mathrm{~kb}, 4.6 \mathrm{~kb}$ and $2 \mathrm{~kb}$ upstream (Fig: 9a), and the consensus sequence "GGTGGAA" [Sander et al., 1997] was located at $3.4 \mathrm{~kb}, 2.9 \mathrm{~kb}$ and $2 \mathrm{~kb}$ (Fig: 9a) upstream of CRALBP exon1. In order to perform Chromatin immunoprecipitation assay (ChIP), we chose a time point during development where Pax6 is known to be highly active. By E14.5, expression of Pax6 can be detected throughout the anterior- posterior axis of the dorsal telencephalon in the ventricular zone and the subventricular zone [Warren et al., 1999]. DNA-protein complexes isolated from E14.5 cortex were precipitated with Pax6 antibody and amplified using primers against Pax6 binding sites on $C R A L B P$ promoter. Pax6 seems to bind two putative sites on CRALBP promoter, at $2 \mathrm{~kb}$ and $2.9 \mathrm{~kb}$ upstream of exon1 (Fig. 9c). Pax6 also had a weak affinity for a putative site at $3.4 \mathrm{~kb}$ upstream of $C R A L B P$, but this could not be reproduced. In addition to the mentioned Pax6 putative binding sites we were able to locate few other binding sites with one or two nucleotide mismatches which we have not investigated further. This experiment was also repeated by precipitating DNA-protein complexes using Pax6 antibody from Pax6 mutant cortex tissue. As predicted, we did not 
amplify any DNA in the PCR reaction (data not shown). Our in vivo results indicate that Pax6 binds the putative promoter region of $C R A L B P$.

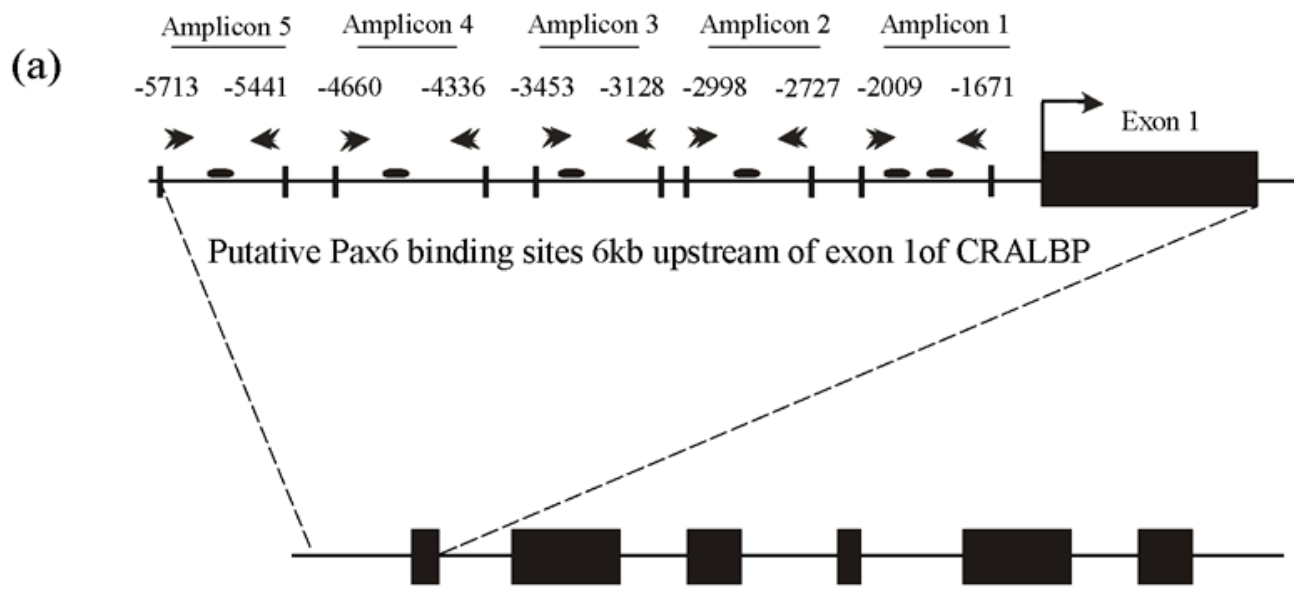

(b)

(c)

$$
\frac{+}{\text { control }} \frac{+}{5}-\frac{+}{4}=\frac{+}{3}=\frac{+}{2}=
$$

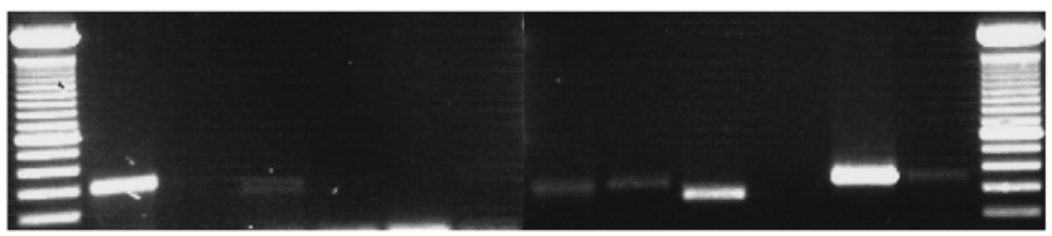

Fig 9: Identification of putative Pax6 binding sites using Chromatin Immunoprecipitation (ChIP) assay. Six putative Pax6 binding sites and the corresponding primers on CRALBP promoter are indicated (a). A known Pax6 binding site on its own promoter was used as a positive control for the PCR (b). PCR amplification for the putative Pax6 binding sites are shown (c). DNA-protein complexes precipitated with Pax6 Ab added (+) and without Ab (-) are indicated. Two Pax6 binding sites were identified. 


\subsubsection{Pax6 activates CRALBP promoter in vitro}

To evaluate whether binding of Pax6 on CRALBP promoter induces expression of CRALBP, a luciferase-reporter assay was performed. CHO cells were transiently cotransfected with Pax6 cDNA plasmids [Walther and Gruss, 1991] and with plasmids that contain luciferase cDNA under the CRALBP promoter [Kennedy et al., 1998]. Cotransfected cells were harvested $16 \mathrm{hrs}$ after transfection and luciferase activity was measured. The reporter activity was significantly increased with increasing concentrations of Pax6 cDNA plasmid, whereas the control G5-luciferase reporter activity showed only a basal level of expression (Fig: 10). This in vitro experiment shows that Pax6 can positively regulate the activity of $C R A L B P$ promoter. 


\section{Luciferase reporter assay}

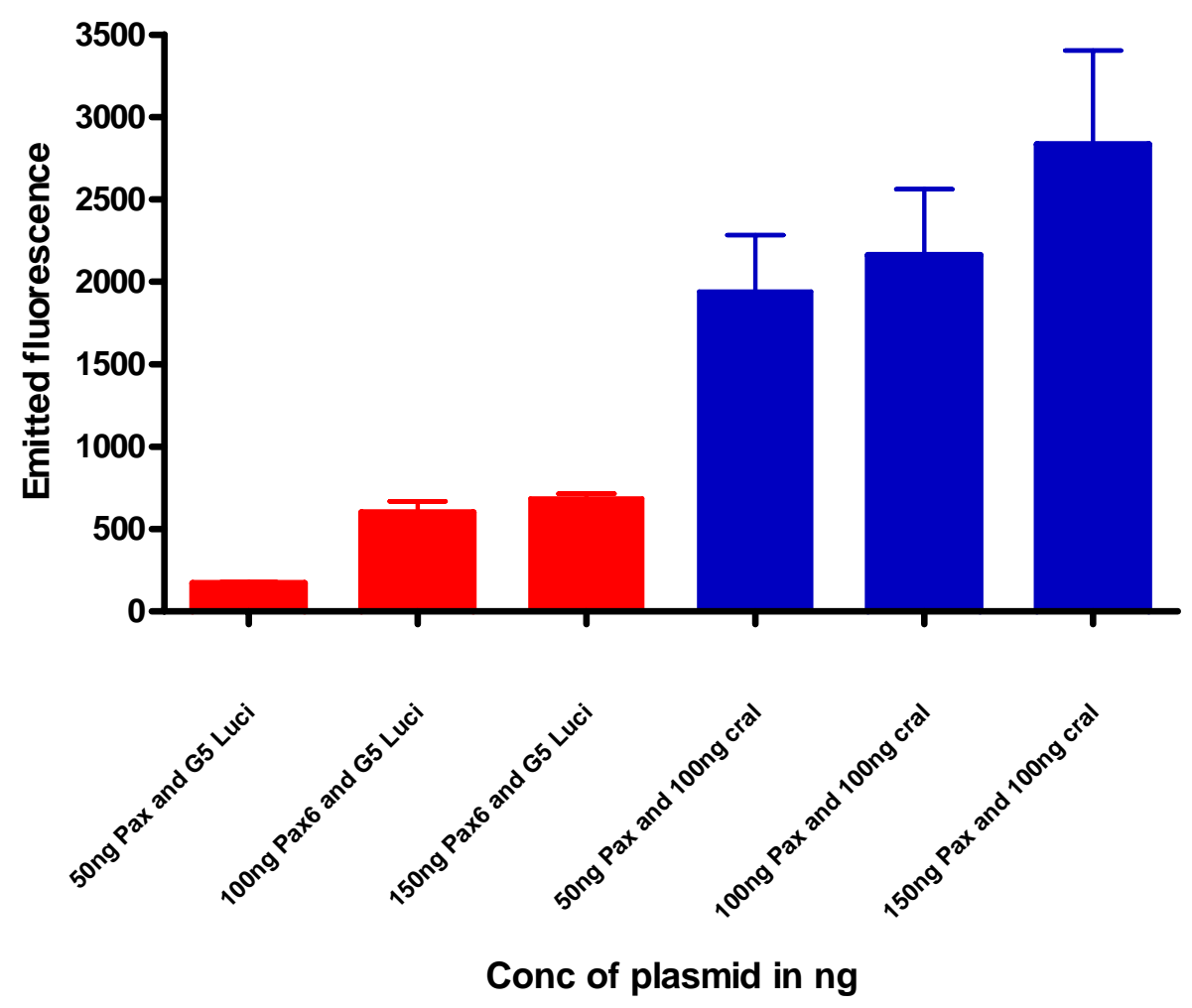

Fig 10: Co-transfection of CHO cells with Pax6 and CRALBP plasmids. Reporter activity of luciferase cDNA under the CRALBP promoter was measured in cells by transfecting them along with Pax6 cDNA plasmid. Increasing concentrations of the latter increases CRALBP-luciferase reporter activity (blue bars). The controls do not show significant increase in activity with increasing concentrations of Pax6 cDNA plasmid (red bars).

\subsubsection{Expression of layer-specific markers indicates no lamination defects in}

\section{CRALBP mutants}

Vitamin A (retinol) and its metabolites (retinaldehyde and retinoic acid) are crucial for development [Goodman, 1984]. Retinoic acid has been shown to induce differentiation of neurons and glia [Tibbles and Wiley, 1988]. Since CRALBP is a carrier of 11-cis-retinol, this could imply that CRALBP might also be involved in similar functions. Hence, we 
expected to find possible lamination problems in CRALBP mutant cortex. For this purpose we looked at the expression of layer specific markers like Satb2 and Ctip2.

Satb2 is a transcription factor mostly expressed in upper layer neurons of the neocortex starting from E13.5 [Britanova et al., 2005]. It regulates gene expression by binding to matrix attachment DNA regions and thus influences chromatin structure [Britanova et al., 2005].

A high majority of Satb $2^{+}$neurons are born between E14.5 and E15.5 in the dorsal telencephalon [Britanova et al., 2006]. At P0 most cells of layers 2-4 express Satb2. Ctip2 is expressed in almost all cortical plate neurons during early stages of cortical development. At later stages, its expression is confined to type I pyramidal neurons of layer 5 [Arlotta et al., 2005].

At E15.5, in both wt and CRALBP mutants, we detected expression of Satb2 and Ctip2 in some migrating neurons and a subpopulation of post migratory neurons in the cortical plate (Fig: 11a, b; d, e). We found atleast 2 populations of neurons- while the majority of cortical plate neurons express only Ctip2, a minority of cells express both Satb2 and Ctip2. We did not observe any difference in the pattern of expression of either marker (Fig: 11c and f) in wt and mutants.

At E17.5, we continued to observe expression of Satb2 and Ctip2 in different subpopulations of migrating neurons (Fig: $11 \mathrm{~g}, \mathrm{j} ; \mathrm{h}, \mathrm{k}$ ). In the cortical plate, differentiated neurons occupying layers 2 to 4 express only Satb2 (Fig: 11g, j), while those of layer 5 
express either Ctip2 or both Ctip2 and Satb2 (Fig: 11i, 1). Weak expression of Ctip2 is also seen in some cells of layer 6 (Fig: 11h, k). In CRALBP mutants, the relative proportions of these neuronal types does not seem to be altered (Fig: 111).

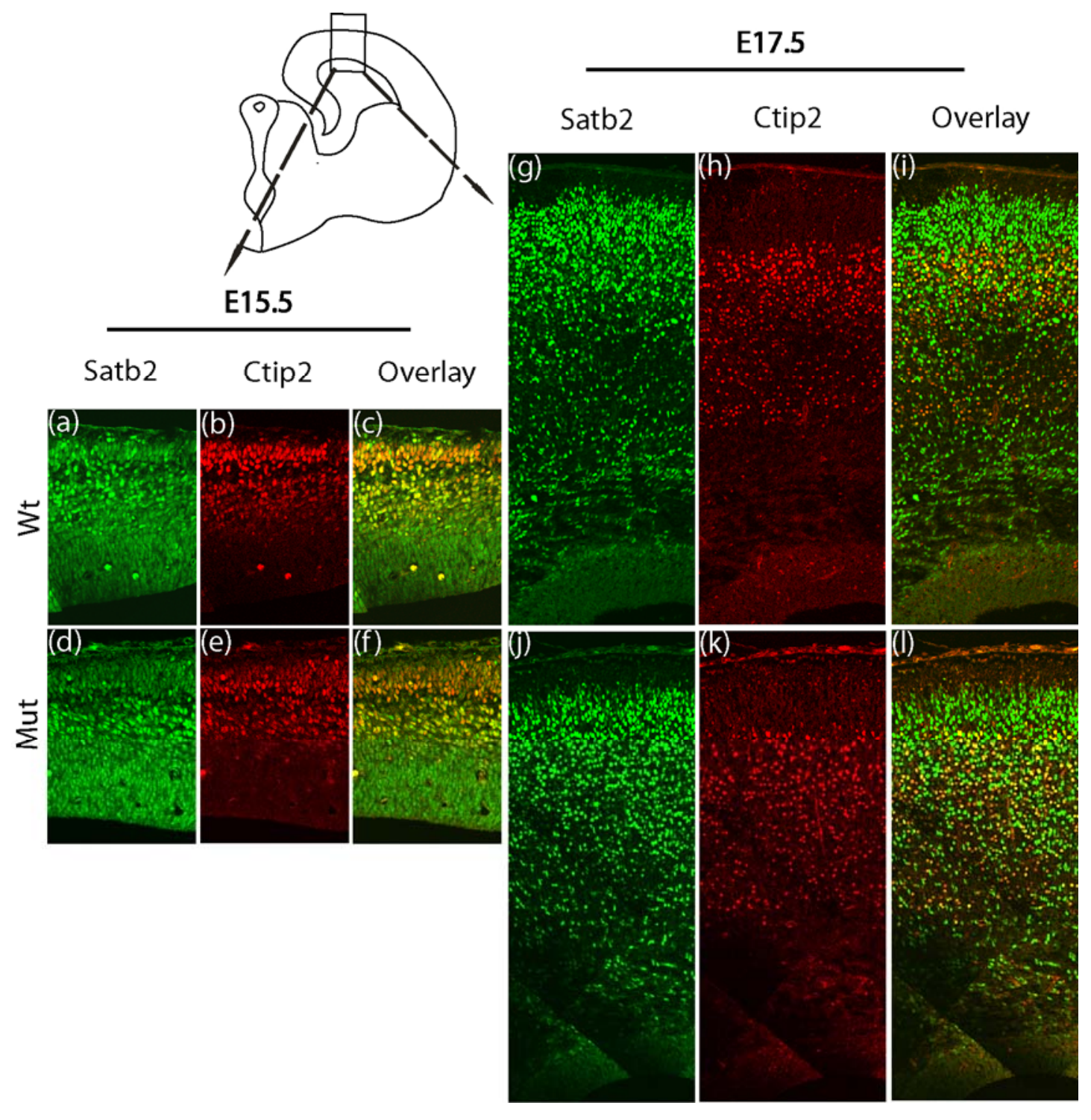

Fig 11: Lamination in wt and CRALBP mutants at E15.5 and E17.5. To determine possible defects in lamination, immunostaining for Satb2 and Ctip2 was done. No differences were observed between wt (a, b, c; g, h and i) and mutant sections (d, e, f; j, k and l). 


\subsubsection{BLBP expressing radial glial processes show a 'wavy' morphology in mutants}

We then wanted to elucidate the function of CRALBP in neocortical VZ, where it was found to be expressed as early as E14.5. For this, we stained radial glial cells with specific markers such as BLBP and Nestin. BLBP is a lipid-binding protein, expressed in radial glial processes early during development. It is known to have a role in neuronal differentiation. Loss of BLBP results in rounding of neuroepithelial cells [Arai et al., 2005]. Nestin is an intermediate filament known to be expressed in all cortical VZ progenitors. At both E15.5 and E17.5, we detected expression of BLBP and Nestin throughout the radial glial processes, extending from ventricular to pial surface (Fig: 12, 13 and 14). We did not find any differences in BLBP staining between wt and mutant at E15.5 (Fig: 12). However, at E17.5, staining with BLBP showed that the radial glial processes possess a wavy morphology in the mutants (Fig: 13). Staining with Nestin failed to recapitulate the same phenotype. (Fig: 14). 

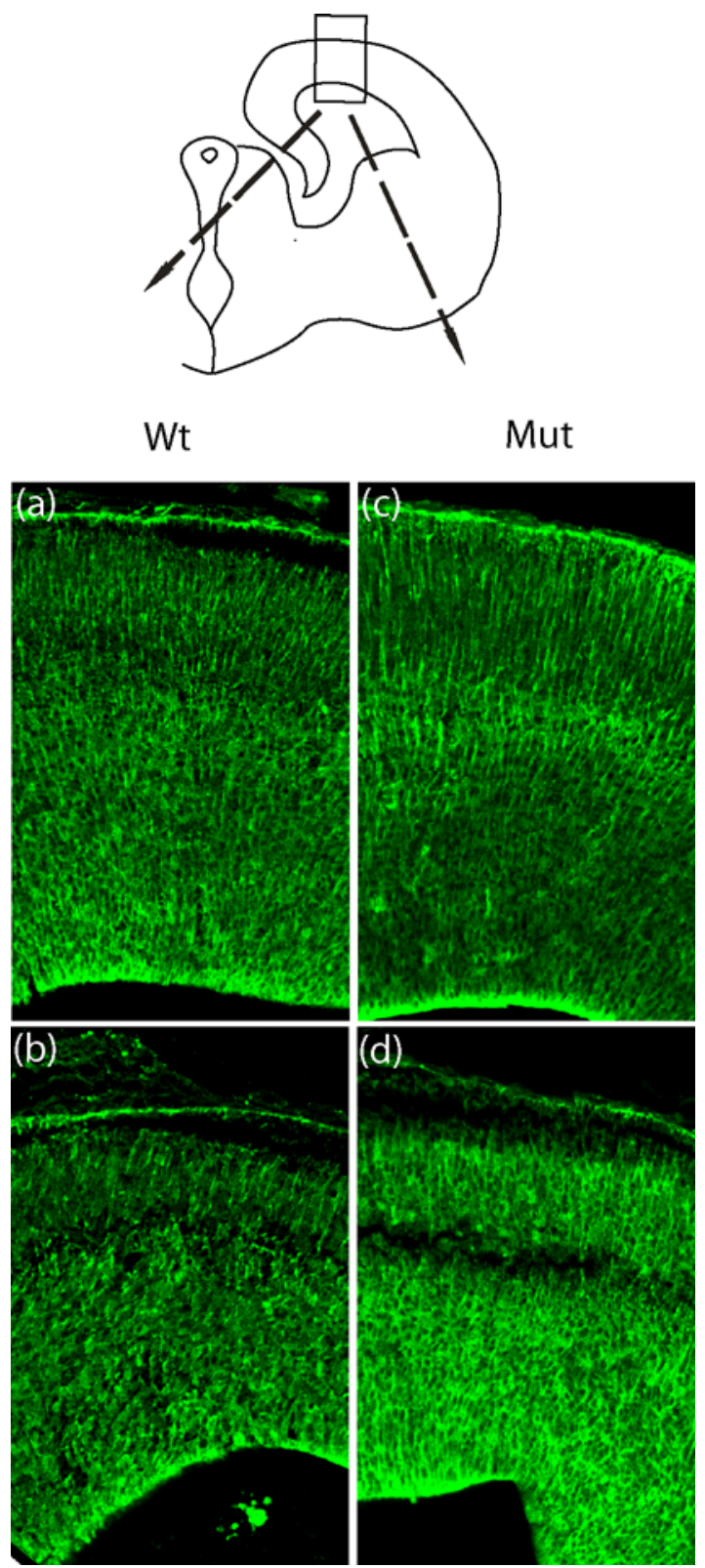

Fig 12: Expression of BLBP in wt and CRALBP mutants at E15.5. Immunostaining for BLBP indicated no difference in expression in mutant cortex (c and d) as compared to wt (a and b). 

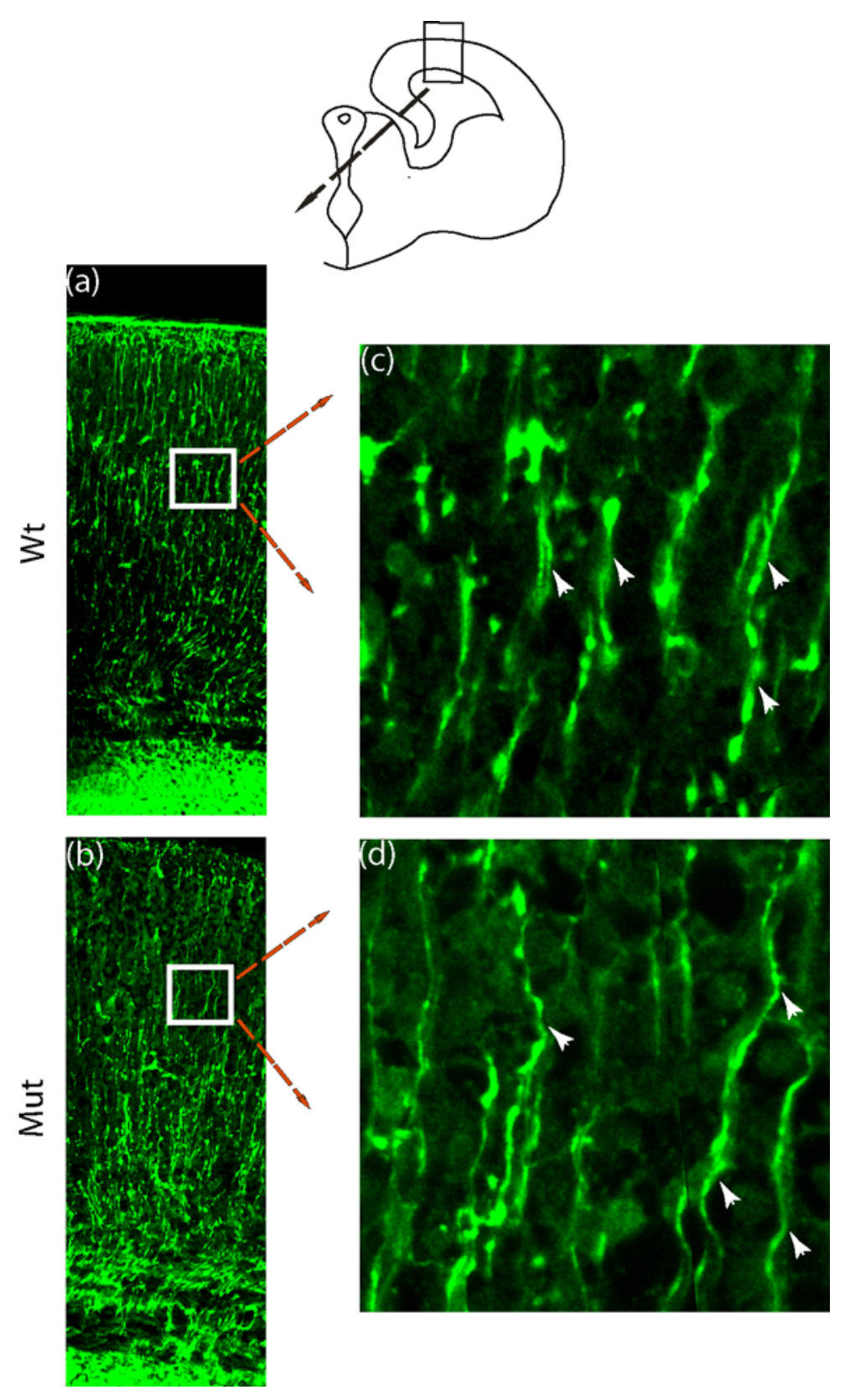

Fig 13: Expression of BLBP in wt and CRALBP mutants at E17.5. Immunostaining for BLBP indicated a "wavy" morphology of radial glial processes in mutant cortex (b; magnified in d) as compared to wt (a; magnified in c). 


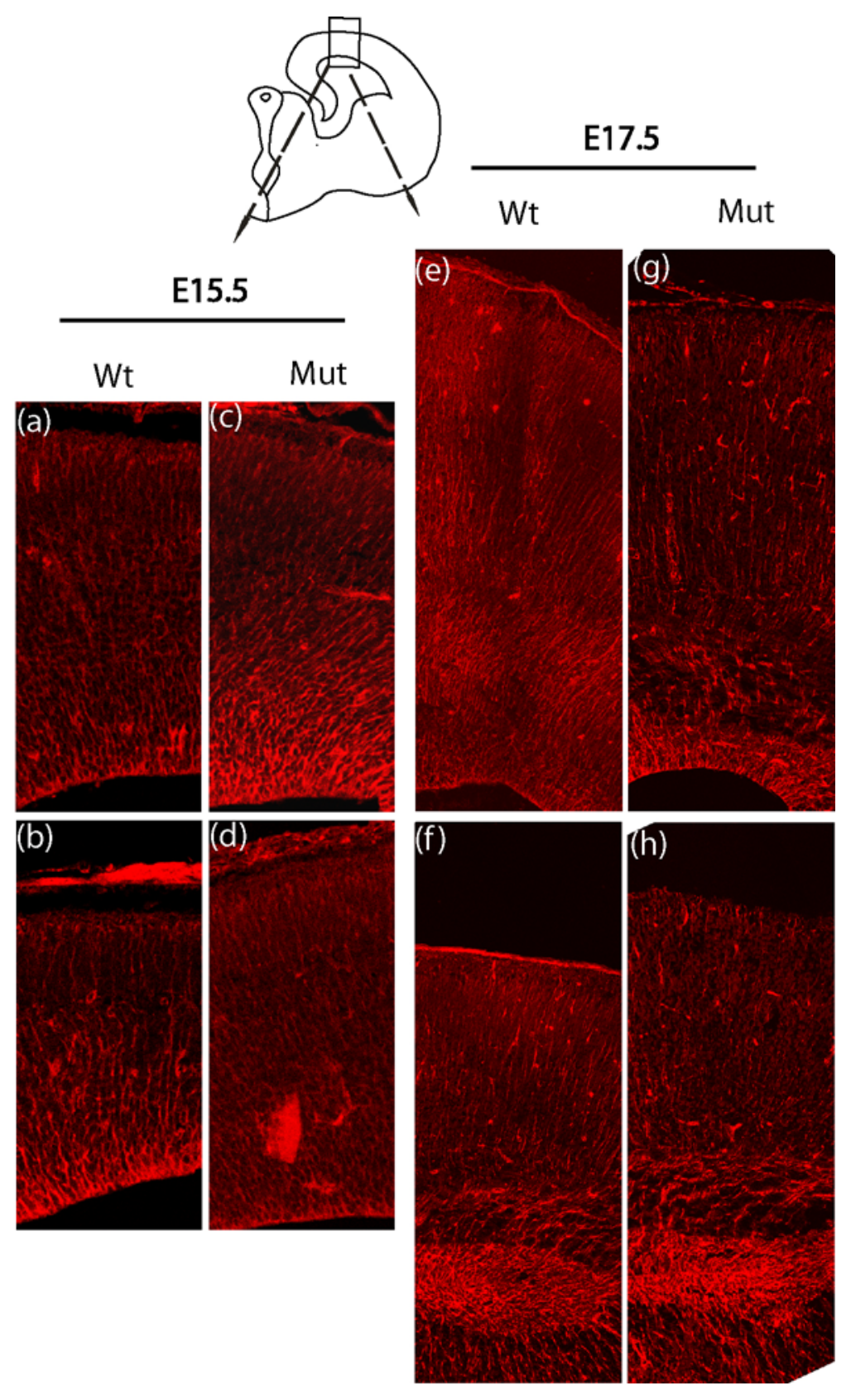

Fig 14: Expression of Nestin in wt and CRALBP mutants. Immunostaining for Nestin at E15.5 and E17.5 indicated no difference in expression in mutant cortex (c, d; g and h) as compared to wt (a, b; e and $\mathrm{f})$. 


\subsection{Analysis of AP2 $\gamma$ function in the cortex}

The expression of AP2 $\gamma$ in Pax6 mutants was downregulated, although not completely abolished. Since Pax6 is known to regulate the expression of many genes during development [Simpson and Price, 2002], we wanted to find out if some effects seen in Pax6 mutants are recapitulated in AP2 $\gamma$ knock out mice. To analyze the expression of some transcription factors (Cux2, Er-81, Id2, LMO4), cell adhesion molecules (Cad8) and the newly described SVZ marker Svet1 [Tarabykin et al., 2001], we performed in situ hybridization. Most of the markers that we selected for in situ analysis were known to be missing, misexpressed, or downregulated in Pax6 mutants.

\subsubsection{Analysis of Cad8 and Id2 expression indicates a shift in Id2 expression boundary}

Cadherin8 (Cad8) is a cell-cell adhesion molecule that shows a distinct pattern of expression across the embryonic neocortex. It is used as a marker of positional identity to study arealization [Bishop et al., 2002]. The caudal boundary of Cad8 expression corresponds to the boundary between motor and somatosensory areas [Suzuki et al., 1997]. In Pax6 mutants, the superficial rostral expression domain of Cad8 is absent.

In wt mice, Id 2 is expressed in layer 5 strongly in the somatosensory cortex and weakly in the motor cortex. This change in expression level takes place abruptly at the boundary between these two areas [Rubenstein et al., 1999]. This boundary between strong and weak layer 5 expression is shifted rostrally in Pax6 mutants. In addition to layer 5, Id2 is strongly expressed in layers 2 and 3 of rostral neocortex, the expression level declines 
towards the intermediate area (somatosensory cortex) and finally becomes undetectable towards the caudal neocortex. In Pax6 mutants, this domain is absent.

In AP2 $\gamma$ mutants, we observed expression of Cad8 in layers 2-5 of rostral neocortex and layer 5 of caudal neocortex (Fig: 15c). This pattern of expression was similar to the expression in the wt (Fig: 15b) as previously reported [Nakagawa et al., 1999]. The expression of Id 2 in layers 2 and 3 did not change in AP2 $\gamma$ mutants, but a moderate rostral shift of expression in layer 5 was observed (Fig: 15f). 

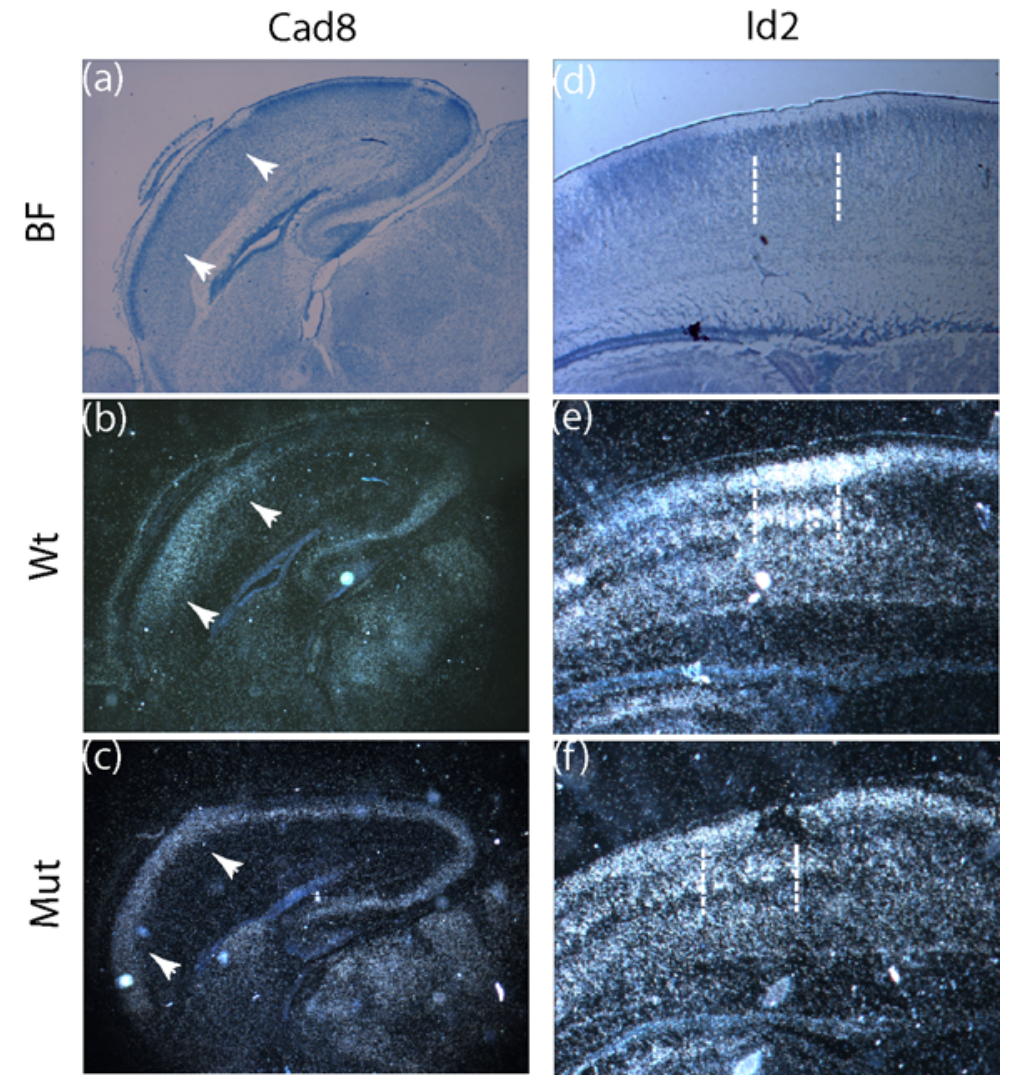

Fig 15: In situ hybridization with Cad8 and Id2 probes in AP2 $\gamma$ mutant. The expression of Cad8 (a-c; arrowheads) and Id2 (d-f; dotted lines) in sagittal sections of wt (b and e) and mutant (c and f) P2 cortex is indicated. Borders of Id2 expression is indicated by dotted lines. A rostral shift in Id 2 expression can be seen (f). The corresponding bright field images are also shown (a and d). Expression of $\mathrm{Cad} 8$ and $\mathrm{Id} 2$ are shown at $2.5 \mathrm{x}$ and $5 \mathrm{x}$ magnification respectively. 


\subsubsection{Expression of Cux2 and Svet1 does not change in the AP2 $\gamma$ mutants}

Cux2 belongs to the family of Cut transcription factors that contain several DNA binding domains. The expression of Cux2 is restricted to the nervous system [Quaggin et al., 1996]. In early embryonic stages Cux2 labels SVZ cells, in adult cortex it is almost exclusively confined to layers 2, 3 and 4 [Nepveu, 2001]. In Pax6 mutant mice Cux2 positive cell number in the SVZ and the upper layers is depleted.

Svet1 (Subventricular tag1) is an embryonic marker of SVZ and specifically marks a subpopulation of cells of the upper layers at postnatal stages [Tarabykin et al., 2001]. In the Pax6/small eye mutant, Svet1 expression was abolished in the SVZ and in the upper cortical layers (layers 2-4) at postnatal stages. The abnormal SVZ cells that lack Svet1 expression do not migrate to the cortical plate; as a result, the SVZ gets overpopulated with cells and expands.

At P2, expression of Cux2 was observed in upper layers of the lateral neocortex but not the medial cortex (Fig: 16b, c). On the other hand, Svet1 was found only in the upper layers of the somatosensory cortex. No difference in expression pattern was found between wt and mutants (Fig: 16e, f).

\subsubsection{Expression of Er81 remains unchanged; expression of LMO4 is decreased}

ER81 belongs to the ETS family of transcription factors [de Launoit et al., 1997] and is expressed in layer 5 pyramidal cells of wt neocortex [Gray et al., 2004; Hevner et al., 2003]. LIM domain only 4 (LMO4) belongs to LMO family of transcription factors that 

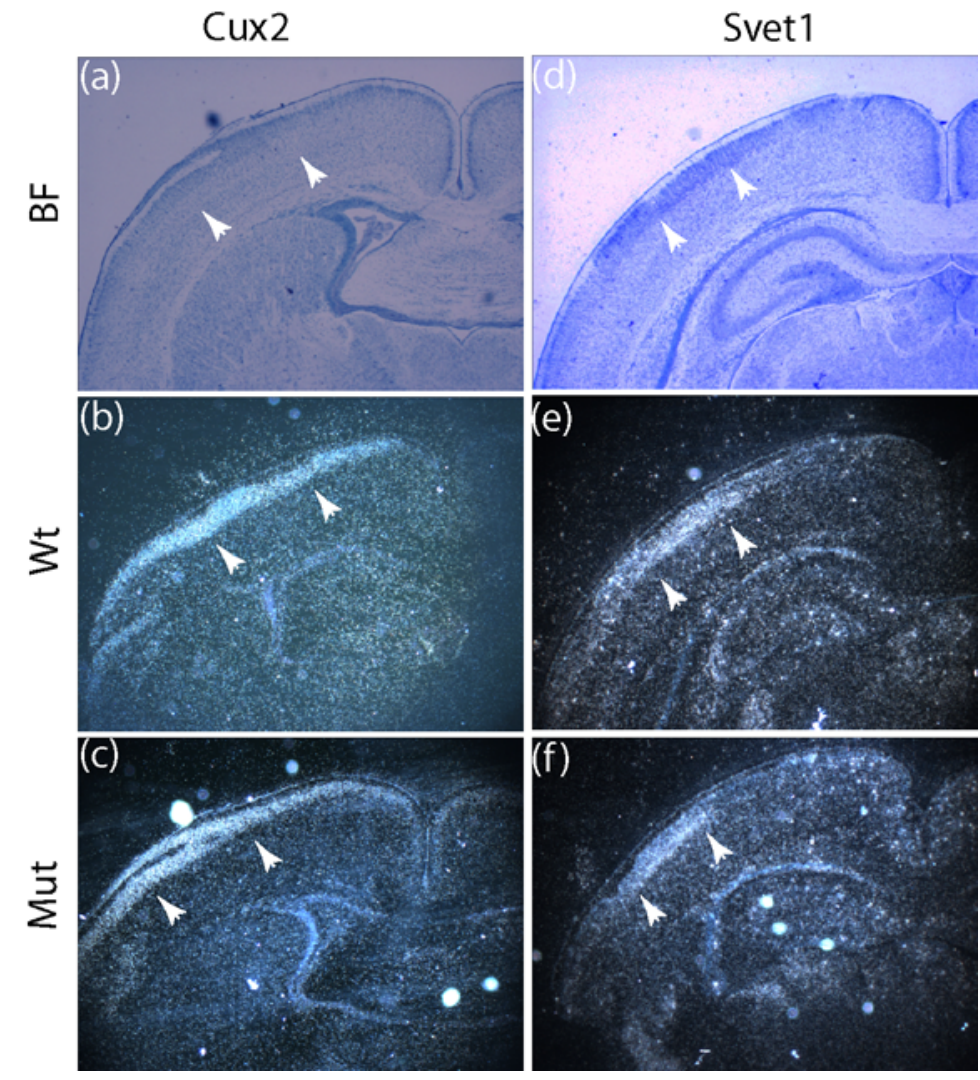

Fig 16: In situ hybridization with Cux2 and Svet1 probes in AP2 $\gamma$ mutant. The expression of Cux2 and Svet1 in frontal sections of wt (b and e) and mutant (c and f) P2 cortex is indicated by arrowheads. No changes in expression can be seen. The corresponding bright field images are also shown (a and d). Expression of Cux2 and Svet1 are shown at 2.5x magnification.

play pivotal roles in proliferation and differentiation of blood cells [Boehm et al., 1991]. Lmo4 is expressed in type II layer 5 pyramidal neurons [Arlotta et al., 2005]. It is also expressed throughout layers 2 and 3 of the posterior cortex [Bulchand et al., 2003]. At P2, we found expression of Er81 in layer 5 throughout the neocortex, extending from medial to piriform cortex. A similar pattern of expression was found in both wt and 
mutant (Fig: 17b, c). LMO4 was expressed only in layer 5 neurons of the medial cortex. In mutants a lower intensity of expression was observed within the same domain (Fig: $17 f)$.
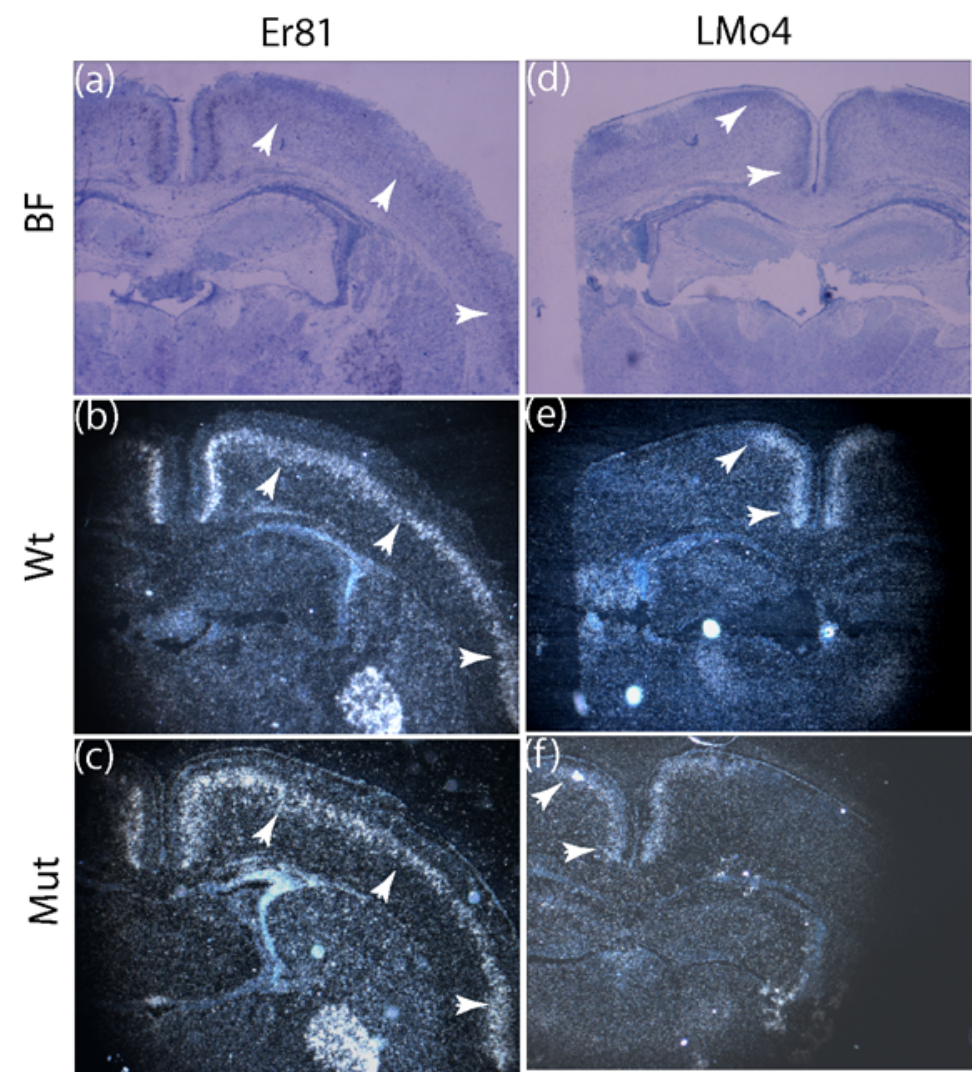

Fig 17: In situ hybridization with Er81 and LMO4 probes in AP2 $\gamma$ mutant. The expression of Er81 and LMO4 in frontal sections of wt ( $b$ and e) and mutant (c and f) P2 cortex is indicated by arrowheads. A decrease in LMO4 expression can be seen. The corresponding bright field images are also shown (a and d). Expression of Er81 and LMO4 are shown at 2.5x magnification. 


\subsubsection{Lamination and proliferation in AP2 $\gamma$ mutants is not affected}

Since AP2 $\gamma$ is known to repress differentiation [Jager et al., 2003], we wanted to study possible lamination problems in AP2 $\gamma$ mutants. For this, we performed immunohistochemistry with layer specific markers, Satb2 and Ctip2. At E17.5 and P2, we observed expression of Satb2 and Ctip2 in migrating neurons as well as differentiated neurons of layers 2 to 4 and layer 5, respectively. In AP2 $\gamma$ mutants, we did not observe any difference in the pattern of expression of either marker (Fig: 18).

Since AP2 $\gamma$ is known to influence proliferation in breast carcinoma, we wanted to see if it performs a similar role in the cortex. For this, Immunohistochemistry was performed to detect expression of the proliferation marker Ki67 at E17.5. As expected, dividing cells were found in the ventricular zone, subventricular zone, and intermediate zone in wt. This domain of Ki67 expression was unaltered in mutants (Fig: 19).

\subsubsection{Pax6 interacts directly with AP2 $\gamma$ promoter}

The downregulation of AP2 $\gamma$ in Pax6 mutants prompted us to investigate if Pax6 regulates the expression of $A P 2 \gamma$ by binding to its putative promoter region. Using E14.5 cortex tissue as the source of DNA, a ChIP assay was performed to see if Pax6 binds to its putative binding sites [Epstein et al., 1994a; Morgan, 2004; Sander et al., 1997] on the promoter of AP2 $\gamma$. DNA-protein complexes were precipitated with Pax6 antibody. Primers that amplify putative Pax6 binding sites on AP $2 \gamma$ promoter were used to amplify DNA precipitated with and without Pax6 Ab (Fig: 20a). Primers were also designed for a known Pax6 binding site on Pax6 promoter [Morgan, 2004] and used as a positive control 
(Fig: 20c). Our results show that Pax6 recognizes two putative sites at $6.8 \mathrm{~kb}$ and $3.1 \mathrm{~kb}$ upstream of exon1 of AP2 $\gamma$ (Fig: 20b). Thus, AP2 $\gamma$ seems to be a direct downstream target of Pax6.

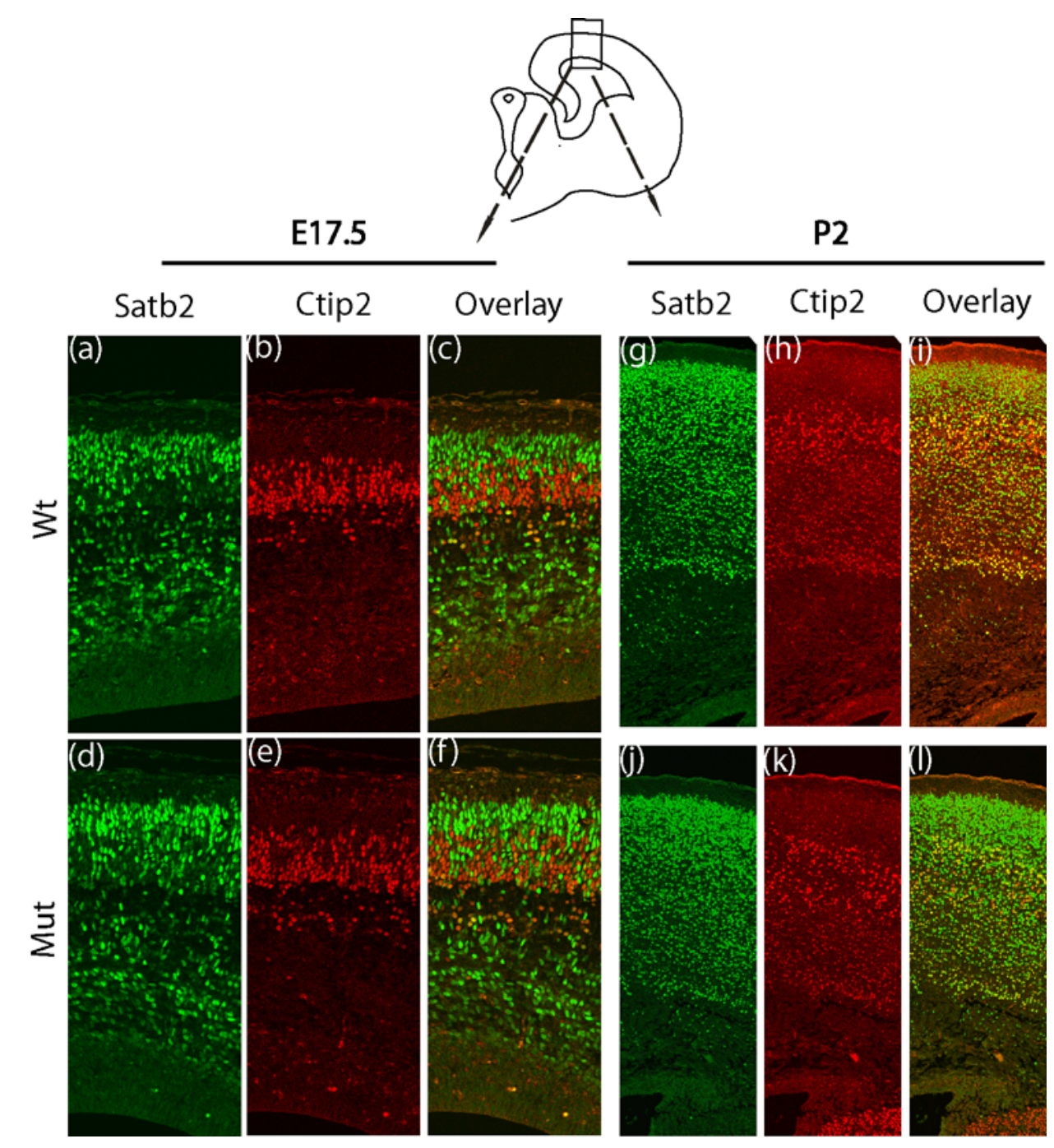

Fig 18: Lamination in wt and AP2 $\gamma$ mutants at E17.5 and P2. To determine possible defects in lamination, immunostaining for Satb2 and Ctip2 was done. No differences were observed between wt (a, b, c; g, h, i) and mutant sections (d, e, f; j, k, l). 

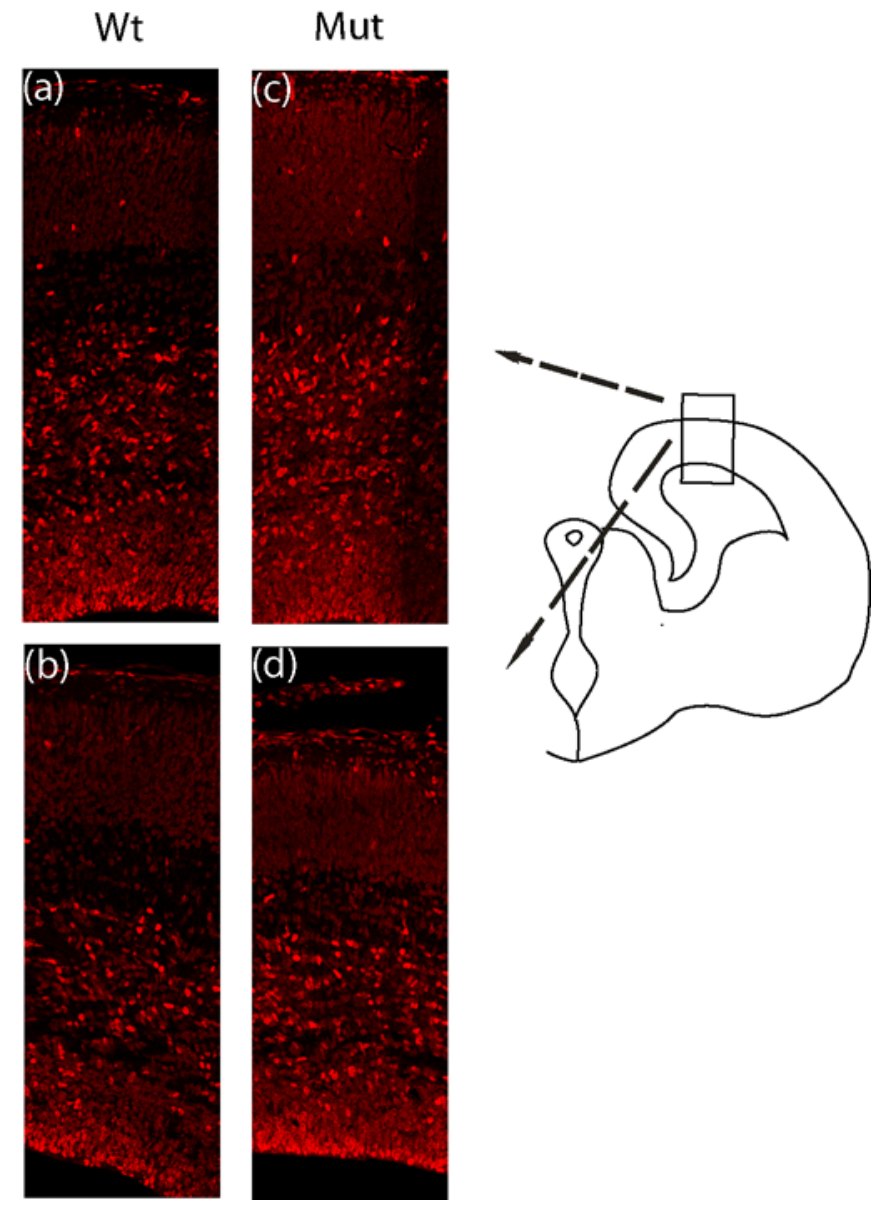

Fig 19: Proliferation in wt and AP2 $\gamma$ mutants at $\mathbf{E}$ 17.5. In order to determine possible changes in proliferation, dividing cells were labeled with proliferative marker Ki-67 using immunohistochemistry. No differences were observed between wt ( $a$ and $b$ ) and mutant sections (c and d). 


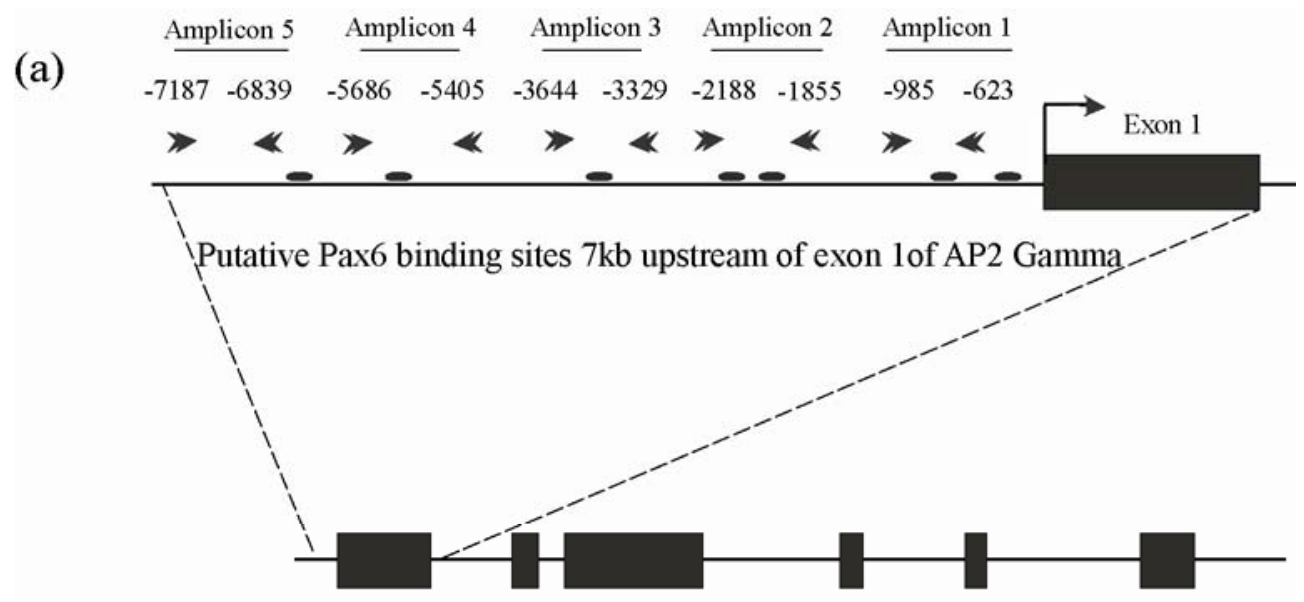

(b)

(c)

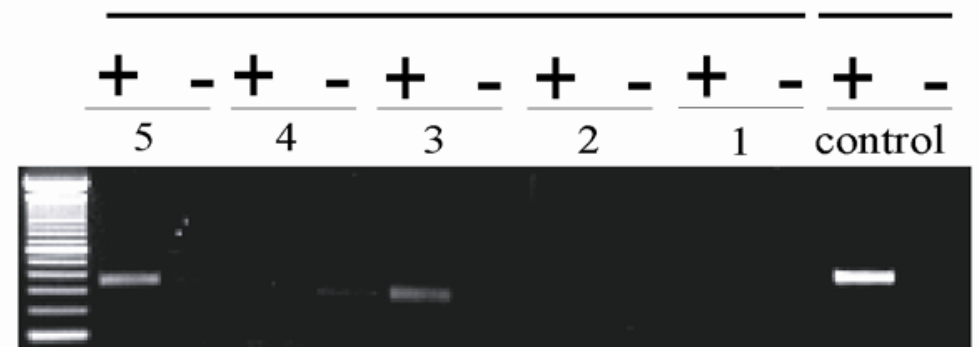

Fig 20: Identification of putative Pax6 binding sites using ChIP assay. Putative Pax6 binding sites (with a few mismatches) and primers to amplify these regions on AP2 $\gamma$ promoter are indicated (a). PCR amplification for putative Pax6 binding sites on AP2 $\gamma$ promoter are shown (b). A known Pax6 binding site on its own promoter was used as a positive control (c). DNA-protein complexes precipitated with Pax6 Ab added (+) and without $\mathrm{Ab}(-)$ are indicated. Pax6 seems to bind to AP2 $\gamma$ promoter region.

\subsubsection{AP2 $\gamma$ does not influence morphology of radial glial processes expressing Nestin}

Loss of Pax6 has been reported to result in a wavy morphology of radial glial processes in the cortex [Gotz et al., 1998]. Since AP2 $\gamma$ is a putative downstream target of Pax6, we wanted to investigate if $\mathrm{AP} 2 \gamma$ has a role in regulating radial glial morphology. We stained radial glial fibers at E15.5 and E17.5 by immunostaining for Nestin, an 
intermediate filament expressed in these processes [Gotz et al., 1998]. No change in Nestin expression was observed in mutants as compared to wt (Fig: 21).

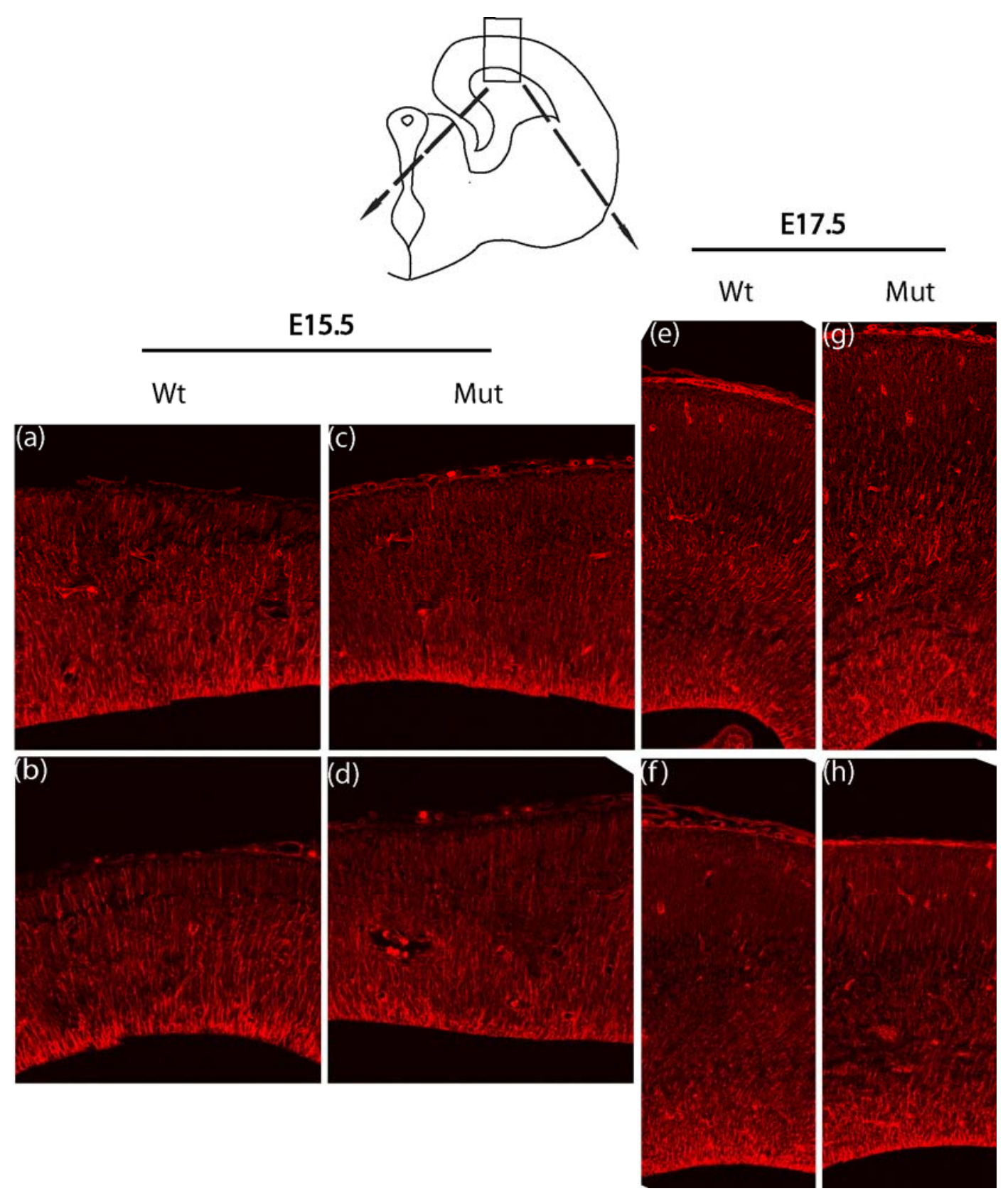

Fig 21: Expression of Nestin in wt and AP2 $\gamma$ mutants. Immunostaining for Nestin, a radial glial marker, at E15.5 and E17.5 indicated no difference in expression in mutant cortex (c, d; g, h) as compared to wt $(a, b ; e, f)$. 


\section{Discussions}

In the current study we investigated downstream pathways of the transcription factor Pax6. In the cortex we identified two genes (AP2 $\gamma$ and CRALBP) whose expression was downregulated in Pax6 mutants and investigated the roles of these genes in cortical development.

\subsection{CRALBP is a direct downstream target of Pax6 and influences radial glial morphology}

Here, we investigate the regulatory activity of Pax6 on CRALBP, a 11- cis retinal binding protein that is mostly expressed in the eye, optic nerve, pineal gland and brain [Saari and Crabb, 2005]. Through microarray experiments we could identify CRALBP to be downregulated in Pax6 mutants. Pax6 is expressed in the ventricular zone (VZ), cortical hem, pallial/subpallial (PSPB) boundary and the thalamus [Manuel and Price, 2005] (Fig: 4b). CRALBP was found to be expressed in all these regions at the mRNA level (Fig: 4c). The borders of CRALBP protein expression corresponded with Pax6 in the cortical hem (Fig: 6a-c), PSPB (Fig: 6d-f), epithalamus (Fig: 7a-c) and hypothalamus (Fig: 7d-f). We did not find regions expressing CRALBP but not Pax6.

CRALBP transcripts were found only in the VZ of the cortex (Fig: 4c), whereas protein expression was observed throughout the cortical plate and the cortical hem (Fig: 6e and 6b). The localization of CRALBP protein in cells of the cortex seemed to be cytoplasmic, as expected. However, we were not able to see radial glial processes through 
immunostaining for CRALBP. There are three possible ways to explain why CRALBP protein is detected all over the cortex while the mRNA is seen only in the VZ. One, young neurons derived from cortical progenitors in the VZ express CRALBP under the transcriptional regulation of Pax6. Even though these neurons migrate away from the VZ towards the cortical plate, we continue to observe expression of CRALBP protein possibly due to increased stability and low turnover rate of the protein. Second, synthesis of CRALBP protein takes place in the VZ; this protein is then transported along radial glial processes towards the pial surface. This however does not explain why CRALBP staining cannot delineate individual radial glial processes. The third explanation could be rapid degradation of CRALBP mRNA in the cortical plate.

Pax6 is also expressed in the differentiating field of the amygdala and in the hypothalamus surrounding the third ventricle (Fig: $4 \mathrm{~b}$; indicated by double arrow heads). However, we did not find expression of CRALBP in these regions (Fig: 4c). Since the expression of a gene not only depends on the binding of transcription factors but also certain cofactors, we suspect that the cofactors required for CRALBP expression could be lacking in these regions.

Abolishment of CRALBP expression in the spinal cord of Pax6 mutants (Fig: 5d) indicates that CRALBP is a target of Pax6 not only in the cortex but also in other regions of the central nervous system. This also implies that CRALBP might play a role in Pax6 mediated development of the spinal cord. 
Using chromatin immunoprecipitation assay, we showed that Pax6 binds to two sites upstream of exon 1 of CRALBP gene, at $2 \mathrm{~kb}$ and $2.9 \mathrm{~kb}$ (Fig: 9c). Although we could not find any TATA or CAAT boxes between the start site and the first Pax6 binding site, we could confirm the regulatory activity of Pax6 on CRALBP expression through in vitro luciferase reporter assay. The increase in reporter activity with increasing concentration of Pax6 (Fig: 10) shows that Pax6 positively regulates the expression of $C R A L B P$.

Pax6 is considered a master regulatory gene of the eye [Gehring, 1996]. We found expression of Pax6 in the neuroretina (NR), (Fig: 8a) and that of CRALBP in the retinal pigment epithelium (RPE) that surrounds the neuroretina (Fig: 8b). During eye morphogenesis, Pax6 is expressed in the optic vesicle (OV) and the surface ectoderm (SE) that surrounds the OV. SE thickens to form the lens placoid (LP), whereas the distal $\mathrm{OV}$ invaginates to form the optic cup (OC) with the inner layer developing into the NR [Ashery-Padan and Gruss, 2001]. The optic vesicle contains bipotential progenitors which can give rise to both RPE and NR cell types. Separation of progenitors into NR and RPE domains is mediated by external cues [Fuhrmann et al., 2000; Pittack et al., 1997]. We believe that expression of Pax6 in the bipotential progenitor cells of the OV promotes CRALBP expression. After receiving signals from external cues, the bipotential progenitors differentiate into NR and RPE cells. The RPE (expressing CRALBP) then migrate and occupy the periphery surrounding the NR (Fig: 8b). After the optic cup is formed, Pax6 is downregulated in the optic stalk and the RPE, but retained in the neuroretina [Ashery-Padan and Gruss, 2001]. This could possibly explain the expression of CRALBP and Pax6 in distinct non- overlapping regions of the eye (Fig: 8c). 
Vitamin A (retinol) and its metabolites (retinaldehyde and retinoic acid) are known for their role in development and maintenance of tissues in many higher animals [Goodman, 1984]. Retinol is metabolized to its bioactive derivative, all-trans-retinoic acid (ATRA) which is synthesized in discrete regions of the brain [Dev et al., 1993]. Retinoic acid (RA) is used for neural induction in embryonic stem cells [Bain et al., 1995; Bain et al., 1996] and has been shown to promote differentiation of excitatory and inhibitory neurons and glia [Finley et al., 1996].

CRALBP belongs to the class of retinoid binding proteins (RBPs) which are carriers of retinol and its derivatives [Vieira et al., 1995]. We found CRALBP transcripts as early as E12.5 in wt cortex (data not shown). By E14.5 expression of CRALBP protein was observed throughout the cortical plate (Fig: 6e) indicating that CRALBP could play a role during early corticogenesis. Early cortical development is associated with proliferation and neuronal migration that requires the aid of radial glial processes, long regarded primarily as a scaffold for migrating neurons [Rakic, 2003]. Immunostaining for BLBP indicated alterations in radial glial morphology in CRALBP mutants (Fig: 13). BLBP belongs to the family of Fatty acid-binding proteins (FABPs) which are a conserved multigene family of intracellular lipid binding proteins (iLBPs). Gene duplications in iLBPs gave rise to four subfamilies [Hanhoff et al., 2002]. Subfamily I comprises proteins that bind vitamin A derivatives like CRABPs and CRBPs [Ross, 1993]. Both CRALBP and BLBP are therefore carrier proteins that are evolutionarily linked. It has been shown that BLBP is a downstream target of Pax6 in rats [Arai et al., 2005] and 
knock-down of BLBP using small interfering RNA (siRNAs) results in rounded neuroepithelial cells. BLBP expressing radial glial cells in the cortex of wt mice have straight processes that run from the ventricular surface towards the pial surface (Fig: 12 and 13c). However, in CRALBP mutants these processes have a "wavy" morphology (Fig: 13d). This phenotype recapitulates the radial glial morphology observed in Pax6 mutants [Gotz et al., 1998]. It is however subtle in comparison. We believe that both CRALBP and BLBP contribute to specification of radial glial morphology. In addition to BLBP, we also investigated the expression of Nestin (Fig: 14). Here we did not find the "wavy" phenotype that we observed with BLBP staining in CRALBP mutants. It has been shown that in Pax6 mutants, morphological alterations of radial glial cells can be observed with radial cell 2 (RC2) immunostaining [Gotz et al., 1998]. The authors report that while almost all Pax6-positive cells express RC2, a high proportion of Pax6-negative cells express Nestin [Gotz et al., 1998]. Since Nestin is not expressed in a high majority of Pax6- positive radial glial cells, we assume that the morphological effects mediated by deletion of Pax6, cannot be recapitulated in Nestin-positive cells via CRALBP.

CRALBP is the carrier of 11-cis-retinol in Muller glial cells of the eye. Muller glial cells of the retina have recently been shown to form neurospheres and express CRALBP [Monnin et al., 2007]. Retinol and its metabolites are known for their role in development [Goodman, 1984]. The impairment of 11-cis-retinol transport in CRALBP mutants could lead to decreased activity of RA signaling. Retinoic acid has previously been shown to induce Pax6 expression efficiently in embryoid bodies [Gajovic et al., 1997]. Low activity of RA signaling could result in decreased induction of Pax6 expression, thereby 
partly contributing to the "wavy" phenotype of radial glial cell processes in CRALBP mutants.

We did not observe any defects in either layer-specification or migration of neurons in CRALBP mutants (Figs: 11). However, it is probable that other RBP's expressed in the brain compensate for the loss of CRALBP to some extent thereby leading to a relatively mild phenotype of "wavy" radial glial processes. Our data suggest that CRALBP acts downstream of Pax6 in regulating radial glial morphology.

\subsection{AP2 $\gamma$ does not regulate lamination and proliferation but might influence arealization of the cortex}

The AP2 family of transcription factors consists of five members that are [Zhao et al., 2001] mainly involved in cell proliferation and differentiation. AP2 $\gamma$ has previously been demonstrated to be essential for early embryogenesis [Werling and Schorle, 2002a]. Through microarray experiments we found that expression of AP2 $\gamma$ was downregulated in Pax6 mutants. We then investigated the phenotype of AP2 $\gamma$ mutants in the cerebral cortex. We did not observe any differences in arealization or regionalization using markers like Cad8, Cux2, Svet1 or Er-81 (Figs: 15, 16 and 17 respectively). However, we could find some differences in the expression of Id2 (Fig: 15f) and LMO4 (Fig: 17f).

We found weaker expression of LMO4 in layer 5 in mutants as compared to wt (Fig: 17ef). It has previously been suggested that LMO4 could be a downstream target of fibroblast growth factor receptor 1 (FGFR1) [Saga et al., 1997]. Several putative binding 
sites of AP2 transcription factors have been located on FGFR3 [Perez-Castro et al., 1997]. This might explain the regulatory role of AP2 transcription factors on FGFR genes. AP2 $\gamma$ could also regulate the expression of LMO4 by regulating the expression of FGFR1. However, we have not attempted to look for putative binding sites of AP2 $\gamma$ in the promoter region of FGFR1. Since putative binding sites of AP2 genes are known [Hilger-Eversheim et al., 2000], it would be interesting to investigate this possibility. In vivo binding assays could provide better insight on transcriptional regulation by AP $2 \gamma$.

It has been reported that overexpression of $\mathrm{AP} 2 \gamma$ promotes proliferation and impairs differentiation [Jager et al., 2003]. Therefore, in AP2 $\gamma$ mutants, impaired proliferation and premature differentiation can be expected. Premature differentiation can often lead to problems in lamination. To verify this, layer specific populations of neurons were labeled with markers like Satb2 (layers 2-4) and Ctip2 (layer5). We did not find any difference in the size of these populations or their position within the cortex (Fig: 18). This indicates that patterning and layer specification are not affected in AP2 $\gamma$ mutant cortex. At physiological levels, AP2 $\gamma$ probably does not influence differentiation of neurons.

Expression of Id2 marks not only the boundary between motor and somatosensory cortex, but also the lateral boundary of the somatosensory cortex. In AP2 $\gamma$ mutants, this boundary of expression and probably the different cortical areas are shifted rostrally (Fig: 15f). Hence, we believe that AP2 $\gamma$ might be involved in arealization of the cortex. 
AP2 $\gamma$ has been shown to promote proliferation in breast carcinoma [Jager et al., 2005]. However, we did not find any changes in the expression of the cell cycle marker Ki67 in the germinal zones of the neocortex (Fig: 19). Hence, we conclude that AP2 $\gamma$ does not seem to regulate proliferation in this region.

Nestin, a radial glial specific intermediate filament, did not show any differences in expression at E15.5 and E17.5 (Fig: 21) between wt and mutants. Since the possibility for the existence of Nestin positive and Pax6 negative radial glial cells has been shown [Gotz et al., 1998], one could expect to find Nestin positive radial glial processes that do not show any morphological changes on deletion of Pax6.

Since AP2 $\gamma$ is strongly downregulated in Pax6 mutants we looked for Pax6 binding sites on AP2 $\gamma$ promoter. Although we could not find consensus sequences that would indicate putative Pax6 binding sites [Epstein et al., 1994a; Morgan, 2004; Sander et al., 1997], we did find possible Pax6 binding sites with one or two nucleotide mismatches. As Pax6 recognizes an array of different consensus sequences, we began investigating the binding capabilities of Pax6 to these sequences using Chromatin immunoprecipitation assay (ChIP) in combination with semi-quantitative PCR. Our results show that Pax6 binds $A P 2 \gamma$ promoter (Fig: 20b) and possibly regulates its expression. This indicates that $A P 2 \gamma$ could be a direct downstream target of Pax6, which in turn implies that the expression of AP $2 \gamma$ should be completely abolished in Pax6 mutants. However, we did observe a weak expression of AP2 $\gamma$ in these mutants. We therefore believe that cortical progenitors possess alternate pathways to regulate $\mathrm{AP} 2 \gamma$ expression. We are yet to perform luciferase 
reporter assay with $A P 2 \gamma$ promoter constructs and constructs carrying Pax6 coding sequence, to test whether binding of Pax 6 can regulate the expression of $A P 2 \gamma$ gene. In conclusion, it seems that AP2 $\gamma$ does not play a role in lamination or proliferation in the cortex. However, the shift in Id2 expression suggests that it might have a role in arealization. Decrease in LMO4 expression also suggests that AP2 $\gamma$ might be involved in specification of deep layer neurons in the medial cortex. These data indicate the possibility of Id 2 and LMO4 as direct or indirect targets of AP2 $\gamma$. 


\section{Summary}

Transcription factor Pax6 plays an essential role in the development of diverse tissues in vertebrates and invertebrates. It regulates the expression of other transcription factors and cell adhesion molecules, and is crucial for neurogenesis in the developing forebrain. Analysis of gene expression profiles through microarray experiments in Pax6 mutants allowed us to focus on two (AP2 $\gamma$ and CRALBP) of the many genes that were downregulated. We chose these genes since they were expressed in the VZ of the cortex, a proliferative zone known for Pax6 expression. The aim of the project was to analyze if Pax6 mediates some of its functions through these genes.

CRALBP binds 11-cis-retinol with high affinity and acts as a substrate carrier protein. It is expressed in retinal pigment epithelium (RPE) of the eye and is known to have a role in the visual cycle. CRALBP mRNA was expressed in Pax6 expression domains in wt cortex and spinal cord and completely abolished in Pax6 mutants. Protein expression in the brain showed that Pax6 and CRALBP had coinciding boundaries of expression in different regions of the cortex and thalamus. However, in the eye, Pax6 and CRALBP do not share an expression domain. CRALBP promoter was found to contain several putative Pax6 binding sites. We confirmed that Pax6 directly binds CRALBP promoter and positively regulates its expression. Therefore it can be concluded that $C R A L B P$ is a direct downstream target of Pax6.

BLBP expressing radial glial processes in the cortex of CRALBP knockout mouse acquire a wavy morphology, partly recapitulating the phenotype seen in Pax6 mutants. 
This suggests that the morphology of radial glial processes is regulated by Pax6 via CRALBP.

Transcription factor AP2 $\gamma$ positively regulates proliferation and is important for early murine development. Expression analysis (mRNA) in AP2 $\gamma$ mutants using cortical areaspecific and layer-specific markers showed differences in expression of Id2 and LMO4. While Id 2 showed a shift in expression boundaries, expression of LMO4 was decreased. However, there are no apparent lamination or proliferation defects in AP2 $\gamma$ mutant cortex. We also found that Pax6 binds the putative promoter region of AP2 $\gamma$ gene. This suggests that AP2 $\gamma$ might also be a direct downstream target of Pax6. 


\section{Conclusions}

In the current study we investigated the role of CRALBP and AP2 $\gamma$, putative downstream targets of Pax6, in cortical development.

RNA and protein expression data show that CRALBP expression was completely lacking in Pax6 mutants. We also show that Pax6 binds the promoter of CRALBP and activates its expression. Therefore, we conclude that CRALBP is a direct downstream target of Pax6. Also, in CRALBP mutants, radial glial processes acquire a wavy morphology that partly recapitulates the phenotype seen in Pax6 mutants. Thus, it can be concluded that Pax6 regulates radial glial morphology via CRALBP.

We also investigated the role of AP $2 \gamma$ in the cerebral cortex by conditional gene inactivation. We did not find lamination problems or changes in proliferation in AP2 $\gamma$ mutants. We found that Pax6 directly interacts with AP $2 \gamma$ promoter. 


\section{References}

Arai, Y., Funatsu, N., Numayama-Tsuruta, K., Nomura, T., Nakamura, S. and Osumi, N. (2005). Role of Fabp7, a downstream gene of Pax6, in the maintenance of neuroepithelial cells during early embryonic development of the rat cortex. $J$ Neurosci 25, 9752-61.

Arlotta, P., Molyneaux, B. J., Chen, J., Inoue, J., Kominami, R. and Macklis, J. D. (2005). Neuronal subtype-specific genes that control corticospinal motor neuron development in vivo. Neuron 45, 207-21.

Ashery-Padan, R., Marquardt, T., Zhou, X. and Gruss, P. (2000). Pax6 activity in the lens primordium is required for lens formation and for correct placement of a single retina in the eye. Genes Dev 14, 2701-11.

Ashery-Padan, R. and Gruss, P. (2001). Pax6 lights-up the way for eye development. Curr Opin Cell Biol 13, 706-14.

Auman, H. J., Nottoli, T., Lakiza, O., Winger, Q., Donaldson, S. and Williams, T. (2002). Transcription factor AP-2gamma is essential in the extra-embryonic lineages for early postimplantation development. Development 129, 2733-47.

Bain, G., Kitchens, D., Yao, M., Huettner, J. E. and Gottlieb, D. I. (1995). Embryonic stem cells express neuronal properties in vitro. Dev Biol 168, 342-57.

Bain, G., Ray, W. J., Yao, M. and Gottlieb, D. I. (1996). Retinoic acid promotes neural and represses mesodermal gene expression in mouse embryonic stem cells in culture. Biochem Biophys Res Commun 223, 691-4.

Bishop, K. M., Rubenstein, J. L. and O'Leary, D. D. (2002). Distinct actions of Emx1, Emx2, and Pax6 in regulating the specification of areas in the developing neocortex. $J$ Neurosci 22, 7627-38.

Blank, V. and Andrews, N. C. (1997). The Maf transcription factors: regulators of differentiation. Trends Biochem Sci 22, 437-41.

Boehm, T., Foroni, L., Kaneko, Y., Perutz, M. F. and Rabbitts, T. H. (1991). The rhombotin family of cysteine-rich LIM-domain oncogenes: distinct members are involved in T-cell translocations to human chromosomes $11 \mathrm{p} 15$ and $11 \mathrm{p} 13$. Proc Natl Acad Sci U S A 88, 4367-71. 
Bopp, D., Burri, M., Baumgartner, S., Frigerio, G. and Noll, M. (1986). Conservation of a large protein domain in the segmentation gene paired and in functionally related genes of Drosophila. Cell 47, 1033-40.

Bosher, J. M., Totty, N. F., Hsuan, J. J., Williams, T. and Hurst, H. C. (1996). A family of AP-2 proteins regulates c-erbB-2 expression in mammary carcinoma. Oncogene 13, 1701-7.

Briscoe, J. and Ericson, J. (1999). The specification of neuronal identity by graded Sonic Hedgehog signalling. Semin Cell Dev Biol 10, 353-62.

Briscoe, J., Pierani, A., Jessell, T. M. and Ericson, J. (2000). A homeodomain protein code specifies progenitor cell identity and neuronal fate in the ventral neural tube. Cell 101, 435-45.

Britanova, O., Akopov, S., Lukyanov, S., Gruss, P. and Tarabykin, V. (2005). Novel transcription factor Satb2 interacts with matrix attachment region DNA elements in a tissue-specific manner and demonstrates cell-type-dependent expression in the developing mouse CNS. Eur J Neurosci 21, 658-68.

Britanova, O., Alifragis, P., Junek, S., Jones, K., Gruss, P. and Tarabykin, V. (2006). A novel mode of tangential migration of cortical projection neurons. Dev Biol 298, 299311.

Bulchand, S., Subramanian, L. and Tole, S. (2003). Dynamic spatiotemporal expression of LIM genes and cofactors in the embryonic and postnatal cerebral cortex. Dev Dyn 226, 460-9.

Bunt-Milam, A. H. and Saari, J. C. (1983). Immunocytochemical localization of two retinoid-binding proteins in vertebrate retina. $J$ Cell Biol 97, 703-12.

Burstedt, M. S., Forsman-Semb, K., Golovleva, I., Janunger, T., Wachtmeister, L. and Sandgren, O. (2001). Ocular phenotype of bothnia dystrophy, an autosomal recessive retinitis pigmentosa associated with an R234W mutation in the RLBP1 gene. Arch Ophthalmol 119, 260-7.

Cai, L., Hayes, N. L., Takahashi, T., Caviness, V. S., Jr. and Nowakowski, R. S. (2002). Size distribution of retrovirally marked lineages matches prediction from population measurements of cell cycle behavior. J Neurosci Res 69, 731-44. 
Campbell, K. and Gotz, M. (2002). Radial glia: multi-purpose cells for vertebrate brain development. Trends Neurosci 25, 235-8.

Carriere, C., Plaza, S., Martin, P., Quatannens, B., Bailly, M., Stehelin, D. and Saule, S. (1993). Characterization of quail Pax-6 (Pax-QNR) proteins expressed in the neuroretina. Mol Cell Biol 13, 7257-66.

Chapouton, P., Gartner, A. and Gotz, M. (1999). The role of Pax6 in restricting cell migration between developing cortex and basal ganglia. Development 126, 5569-79.

Chazaud, C., Oulad-Abdelghani, M., Bouillet, P., Decimo, D., Chambon, P. and Dolle, P. (1996). AP-2.2, a novel gene related to AP-2, is expressed in the forebrain, limbs and face during mouse embryogenesis. Mech Dev 54, 83-94.

Chow, R. L., Altmann, C. R., Lang, R. A. and Hemmati-Brivanlou, A. (1999). Pax6 induces ectopic eyes in a vertebrate. Development 126, 4213-22.

Czerny, T., Schaffner, G. and Busslinger, M. (1993). DNA sequence recognition by Pax proteins: bipartite structure of the paired domain and its binding site. Genes Dev 7, 2048-61.

Dahmane, N., Sanchez, P., Gitton, Y., Palma, V., Sun, T., Beyna, M., Weiner, H. and Ruiz i Altaba, A. (2001). The Sonic Hedgehog-Gli pathway regulates dorsal brain growth and tumorigenesis. Development 128, 5201-12.

de Launoit, Y., Baert, J. L., Chotteau, A., Monte, D., Defossez, P. A., Coutte, L., Pelczar, H. and Leenders, F. (1997). Structure-function relationships of the PEA3 group of Ets-related transcription factors. Biochem Mol Med 61, 127-35.

Dev, S., Adler, A. J. and Edwards, R. B. (1993). Adult rabbit brain synthesizes retinoic acid. Brain Res 632, 325-8.

Dowling, J. E. (1960). Chemistry of visual adaptation in the rat. Nature 188, 114-8.

Echelard, Y., Epstein, D. J., St-Jacques, B., Shen, L., Mohler, J., McMahon, J. A. and McMahon, A. P. (1993). Sonic hedgehog, a member of a family of putative signaling molecules, is implicated in the regulation of CNS polarity. Cell 75, 1417-30.

Englund, C., Fink, A., Lau, C., Pham, D., Daza, R. A., Bulfone, A., Kowalczyk, T. and Hevner, R. F. (2005). Pax6, Tbr2, and Tbr1 are expressed sequentially by radial glia, intermediate progenitor cells, and postmitotic neurons in developing neocortex. $J$ Neurosci 25, 247-51. 
Epstein, J., Cai, J., Glaser, T., Jepeal, L. and Maas, R. (1994a). Identification of a Pax paired domain recognition sequence and evidence for DNA-dependent conformational changes. J Biol Chem 269, 8355-61.

Epstein, J. A., Glaser, T., Cai, J., Jepeal, L., Walton, D. S. and Maas, R. L. (1994b). Two independent and interactive DNA-binding subdomains of the Pax6 paired domain are regulated by alternative splicing. Genes Dev 8, 2022-34.

Ericson, J., Rashbass, P., Schedl, A., Brenner-Morton, S., Kawakami, A., van Heyningen, V., Jessell, T. M. and Briscoe, J. (1997). Pax6 controls progenitor cell identity and neuronal fate in response to graded Shh signaling. Cell 90, 169-80.

Finley, M. F., Kulkarni, N. and Huettner, J. E. (1996). Synapse formation and establishment of neuronal polarity by P19 embryonic carcinoma cells and embryonic stem cells. J Neurosci 16, 1056-65.

Fode, C., Ma, Q., Casarosa, S., Ang, S. L., Anderson, D. J. and Guillemot, F. (2000). A role for neural determination genes in specifying the dorsoventral identity of telencephalic neurons. Genes Dev 14, 67-80.

Frantz, G. D., Bohner, A. P., Akers, R. M. and McConnell, S. K. (1994). Regulation of the POU domain gene SCIP during cerebral cortical development. J Neurosci 14, 47285.

Fuhrmann, S., Levine, E. M. and Reh, T. A. (2000). Extraocular mesenchyme patterns the optic vesicle during early eye development in the embryonic chick. Development 127, 4599-609.

Gajovic, S., St-Onge, L., Yokota, Y. and Gruss, P. (1997). Retinoic acid mediates Pax6 expression during in vitro differentiation of embryonic stem cells. Differentiation 62, 187-92.

Gehring, W. J. (1996). The master control gene for morphogenesis and evolution of the eye. Genes Cells 1, 11-5.

Gerhart, J. (1999). 1998 Warkany lecture: signaling pathways in development. Teratology 60, 226-39.

Goodman, D. S. (1984). Vitamin A and retinoids in health and disease. N Engl J Med 310, 1023-31. 
Gorski, J. A., Talley, T., Qiu, M., Puelles, L., Rubenstein, J. L. and Jones, K. R. (2002). Cortical excitatory neurons and glia, but not GABAergic neurons, are produced in the Emx 1-expressing lineage. J Neurosci 22, 6309-14.

Gotz, M., Stoykova, A. and Gruss, P. (1998). Pax6 controls radial glia differentiation in the cerebral cortex. Neuron 21, 1031-44.

Gotz, M. (2003). Glial cells generate neurons--master control within CNS regions: developmental perspectives on neural stem cells. Neuroscientist 9, 379-97.

Goudreau, G., Petrou, P., Reneker, L. W., Graw, J., Loster, J. and Gruss, P. (2002). Mutually regulated expression of Pax6 and Six 3 and its implications for the Pax6 haploinsufficient lens phenotype. Proc Natl Acad Sci U S A 99, 8719-24.

Graff, J. M. (1997). Embryonic patterning: to BMP or not to BMP, that is the question. Cell 89, 171-4.

Grandbarbe, L., Bouissac, J., Rand, M., Hrabe de Angelis, M., Artavanis-Tsakonas, S. and Mohier, E. (2003). Delta-Notch signaling controls the generation of neurons/glia from neural stem cells in a stepwise process. Development 130, 1391-402.

Gray, P. A., Fu, H., Luo, P., Zhao, Q., Yu, J., Ferrari, A., Tenzen, T., Yuk, D. I., Tsung, E. F., Cai, Z. et al. (2004). Mouse brain organization revealed through direct genome-scale TF expression analysis. Science 306, 2255-7.

Hanhoff, T., Lucke, C. and Spener, F. (2002). Insights into binding of fatty acids by fatty acid binding proteins. Mol Cell Biochem 239, 45-54.

Hasegawa, H., Ashigaki, S., Takamatsu, M., Suzuki-Migishima, R., Ohbayashi, N., Itoh, N., Takada, S. and Tanabe, Y. (2004). Laminar patterning in the developing neocortex by temporally coordinated fibroblast growth factor signaling. $J$ Neurosci $\mathbf{2 4}$, 8711-9.

Haubensak, W., Attardo, A., Denk, W. and Huttner, W. B. (2004). Neurons arise in the basal neuroepithelium of the early mammalian telencephalon: a major site of neurogenesis. Proc Natl Acad Sci U S A 101, 3196-201.

Hevner, R. F., Daza, R. A., Rubenstein, J. L., Stunnenberg, H., Olavarria, J. F. and Englund, C. (2003). Beyond laminar fate: toward a molecular classification of cortical projection/pyramidal neurons. Dev Neurosci 25, 139-51. 
Hilger-Eversheim, K., Moser, M., Schorle, H. and Buettner, R. (2000). Regulatory roles of AP-2 transcription factors in vertebrate development, apoptosis and cell-cycle control. Gene 260, 1-12.

Hill, R. E., Favor, J., Hogan, B. L., Ton, C. C., Saunders, G. F., Hanson, I. M., Prosser, J., Jordan, T., Hastie, N. D. and van Heyningen, V. (1991). Mouse small eye results from mutations in a paired-like homeobox-containing gene. Nature 354, 522-5.

Intres, R., Goldflam, S., Cook, J. R. and Crabb, J. W. (1994). Molecular cloning and structural analysis of the human gene encoding cellular retinaldehyde-binding protein. $J$ Biol Chem 269, 25411-8.

Jager, R., Werling, U., Rimpf, S., Jacob, A. and Schorle, H. (2003). Transcription factor AP-2gamma stimulates proliferation and apoptosis and impairs differentiation in a transgenic model. Mol Cancer Res 1, 921-9.

Jager, R., Friedrichs, N., Heim, I., Buttner, R. and Schorle, H. (2005). Dual role of AP-2gamma in ErbB-2-induced mammary tumorigenesis. Breast Cancer Res Treat 90, 273-80.

Jaworski, C., Sperbeck, S., Graham, C. and Wistow, G. (1997). Alternative splicing of Pax6 in bovine eye and evolutionary conservation of intron sequences. Biochem Biophys Res Commun 240, 196-202.

Johnson, W. and Jameson, J. L. (1999). AP-2 (activating protein 2) and Sp1 (selective promoter factor 1) regulatory elements play distinct roles in the control of basal activity and cyclic adenosine 3',5'-monophosphate responsiveness of the human chorionic gonadotropin-beta promoter. Mol Endocrinol 13, 1963-75.

Jones, S. E. and Jomary, C. (2002). Secreted Frizzled-related proteins: searching for relationships and patterns. Bioessays 24, 811-20.

Kennedy, B. N., Goldflam, S., Chang, M. A., Campochiaro, P., Davis, A. A., Zack, D. J. and Crabb, J. W. (1998). Transcriptional regulation of cellular retinaldehydebinding protein in the retinal pigment epithelium. A role for the photoreceptor consensus element. J Biol Chem 273, 5591-8.

Kriegstein, A. R. and Gotz, M. (2003). Radial glia diversity: a matter of cell fate. Glia 43, 37-43. 
Kroll, T. T. and O'Leary, D. D. (2005). Ventralized dorsal telencephalic progenitors in Pax6 mutant mice generate GABA interneurons of a lateral ganglionic eminence fate. Proc Natl Acad Sci U S A 102, 7374-9.

Lang, R. A. (2004). Pathways regulating lens induction in the mouse. Int J Dev Biol 48 , 783-91.

Li, Q. and Dashwood, R. H. (2004). Activator protein 2alpha associates with adenomatous polyposis coli/beta-catenin and Inhibits beta-catenin/T-cell factor transcriptional activity in colorectal cancer cells. $J$ Biol Chem 279, 45669-75.

Liem, K. F., Jr., Tremml, G., Roelink, H. and Jessell, T. M. (1995). Dorsal differentiation of neural plate cells induced by BMP-mediated signals from epidermal ectoderm. Cell 82, 969-79.

Magdaleno, S., Keshvara, L. and Curran, T. (2002). Rescue of ataxia and preplate splitting by ectopic expression of Reelin in reeler mice. Neuron 33, 573-86.

Malatesta, P., Hack, M. A., Hartfuss, E., Kettenmann, H., Klinkert, W., Kirchhoff, F. and Gotz, M. (2003). Neuronal or glial progeny: regional differences in radial glia fate. Neuron 37, 751-64.

Manuel, M. and Price, D. J. (2005). Role of Pax6 in forebrain regionalization. Brain Res Bull 66, 387-93.

Marquardt, T., Ashery-Padan, R., Andrejewski, N., Scardigli, R., Guillemot, F. and Gruss, P. (2001). Pax6 is required for the multipotent state of retinal progenitor cells. Cell 105, 43-55.

Mastick, G. S. and Andrews, G. L. (2001). Pax6 regulates the identity of embryonic diencephalic neurons. Mol Cell Neurosci 17, 190-207.

McPherson, L. A., Baichwal, V. R. and Weigel, R. J. (1997). Identification of ERF-1 as a member of the AP2 transcription factor family. Proc Natl Acad Sci U S A 94, 4342-7. Mehler, M. F., Mabie, P. C., Zhang, D. and Kessler, J. A. (1997). Bone morphogenetic proteins in the nervous system. Trends Neurosci 20, 309-17.

Mitchell, P. J., Timmons, P. M., Hebert, J. M., Rigby, P. W. and Tjian, R. (1991). Transcription factor AP-2 is expressed in neural crest cell lineages during mouse embryogenesis. Genes Dev 5, 105-19. 
Miyata, T., Kawaguchi, A., Saito, K., Kawano, M., Muto, T. and Ogawa, M. (2004). Asymmetric production of surface-dividing and non-surface-dividing cortical progenitor cells. Development 131, 3133-45.

Monnin, J., Morand-Villeneuve, N., Michel, G., Hicks, D. and Versaux-Botteri, C. (2007). Production of neurospheres from mammalian Muller cells in culture. Neurosci Lett 421, 22-6.

Monuki, E. S., Porter, F. D. and Walsh, C. A. (2001). Patterning of the dorsal telencephalon and cerebral cortex by a roof plate-Lhx2 pathway. Neuron 32, 591-604.

Morgan, R. (2004). Conservation of sequence and function in the Pax6 regulatory elements. Trends Genet 20, 283-7.

Morimura, H., Berson, E. L. and Dryja, T. P. (1999). Recessive mutations in the RLBP1 gene encoding cellular retinaldehyde-binding protein in a form of retinitis punctata albescens. Invest Ophthalmol Vis Sci 40, 1000-4.

Moser, M., Pscherer, A., Roth, C., Becker, J., Mucher, G., Zerres, K., Dixkens, C., Weis, J., Guay-Woodford, L., Buettner, R. et al. (1997a). Enhanced apoptotic cell death of renal epithelial cells in mice lacking transcription factor AP-2beta. Genes Dev 11, 1938-48.

Moser, M., Ruschoff, J. and Buettner, R. (1997b). Comparative analysis of AP-2 alpha and AP-2 beta gene expression during murine embryogenesis. Dev Dyn 208, 115-24.

Muzio, L., DiBenedetto, B., Stoykova, A., Boncinelli, E., Gruss, P. and Mallamaci, A. (2002). Conversion of cerebral cortex into basal ganglia in Emx2(-/-) Pax6(Sey/Sey) double-mutant mice. Nat Neurosci 5, 737-45.

Nakagawa, Y., Johnson, J. E. and O'Leary, D. D. (1999). Graded and areal expression patterns of regulatory genes and cadherins in embryonic neocortex independent of thalamocortical input. $J$ Neurosci 19, 10877-85.

Nelson, W. J. and Nusse, R. (2004). Convergence of Wnt, beta-catenin, and cadherin pathways. Science 303, 1483-7.

Nepveu, A. (2001). Role of the multifunctional CDP/Cut/Cux homeodomain transcription factor in regulating differentiation, cell growth and development. Gene 270, $1-15$. 
Nieto, M., Monuki, E. S., Tang, H., Imitola, J., Haubst, N., Khoury, S. J., Cunningham, J., Gotz, M. and Walsh, C. A. (2004). Expression of Cux-1 and Cux-2 in the subventricular zone and upper layers II-IV of the cerebral cortex. J Comp Neurol 479, 168-80.

Noctor, S. C., Martinez-Cerdeno, V., Ivic, L. and Kriegstein, A. R. (2004). Cortical neurons arise in symmetric and asymmetric division zones and migrate through specific phases. Nat Neurosci 7, 136-44.

Ogawa, M., Miyata, T., Nakajima, K., Yagyu, K., Seike, M., Ikenaka, K., Yamamoto, H. and Mikoshiba, K. (1995). The reeler gene-associated antigen on CajalRetzius neurons is a crucial molecule for laminar organization of cortical neurons. Neuron 14, 899-912.

Parnavelas, J. G. (2000). The origin and migration of cortical neurones: new vistas. Trends Neurosci 23, 126-31.

Perez-Castro, A. V., Wilson, J. and Altherr, M. R. (1997). Genomic organization of the human fibroblast growth factor receptor 3 (FGFR3) gene and comparative sequence analysis with the mouse Fgfr3 gene. Genomics 41, 10-6.

Pfisterer, P., Ehlermann, J., Hegen, M. and Schorle, H. (2002). A subtractive gene expression screen suggests a role of transcription factor AP-2 alpha in control of proliferation and differentiation. J Biol Chem 277, 6637-44.

Pittack, C., Grunwald, G. B. and Reh, T. A. (1997). Fibroblast growth factors are necessary for neural retina but not pigmented epithelium differentiation in chick embryos. Development 124, 805-16.

Quaggin, S. E., Heuvel, G. B., Golden, K., Bodmer, R. and Igarashi, P. (1996). Primary structure, neural-specific expression, and chromosomal localization of Cux-2, a second murine homeobox gene related to Drosophila cut. J Biol Chem 271, 22624-34.

Rakic, P. (2003). Elusive radial glial cells: historical and evolutionary perspective. Glia 43, 19-32.

Richardson, B. D., Langland, R. A., Bachurski, C. J., Richards, R. G., Kessler, C. A., Cheng, Y. H. and Handwerger, S. (2000). Activator protein-2 regulates human placental lactogen gene expression. Mol Cell Endocrinol 160, 183-92. 
Ross, A. C. (1993). Cellular metabolism and activation of retinoids: roles of cellular retinoid-binding proteins. Faseb $J$ 7, 317-27.

Rosso, S. B., Sussman, D., Wynshaw-Boris, A. and Salinas, P. C. (2005). Wnt signaling through Dishevelled, Rac and JNK regulates dendritic development. Nat Neurosci 8, 34-42.

Rubenstein, J. L., Anderson, S., Shi, L., Miyashita-Lin, E., Bulfone, A. and Hevner, R. (1999). Genetic control of cortical regionalization and connectivity. Cereb Cortex 9, 524-32.

Saari, J. C. and Bredberg, L. (1982). Enzymatic reduction of 11-cis-retinal bound to cellular retinal-binding protein. Biochim Biophys Acta 716, 266-72.

Saari, J. C., Bredberg, L. and Garwin, G. G. (1982). Identification of the endogenous retinoids associated with three cellular retinoid-binding proteins from bovine retina and retinal pigment epithelium. $J$ Biol Chem 257, 13329-33.

Saari, J. C., Huang, J., Possin, D. E., Fariss, R. N., Leonard, J., Garwin, G. G., Crabb, J. W. and Milam, A. H. (1997). Cellular retinaldehyde-binding protein is expressed by oligodendrocytes in optic nerve and brain. Glia 21, 259-68.

Saari, J. C., Nawrot, M., Kennedy, B. N., Garwin, G. G., Hurley, J. B., Huang, J., Possin, D. E. and Crabb, J. W. (2001). Visual cycle impairment in cellular retinaldehyde binding protein (CRALBP) knockout mice results in delayed dark adaptation. Neuron 29, 739-48.

Saari, J. C. and Crabb, J. W. (2005). Focus on molecules: cellular retinaldehydebinding protein (CRALBP). Exp Eye Res 81, 245-6.

Saga, Y., Hata, N., Koseki, H. and Taketo, M. M. (1997). Mesp2: a novel mouse gene expressed in the presegmented mesoderm and essential for segmentation initiation. Genes Dev 11, 1827-39.

Sakai, M., Serria, M. S., Ikeda, H., Yoshida, K., Imaki, J. and Nishi, S. (2001). Regulation of c-maf gene expression by Pax6 in cultured cells. Nucleic Acids Res 29, 1228-37.

Sander, M., Neubuser, A., Kalamaras, J., Ee, H. C., Martin, G. R. and German, M. S. (1997). Genetic analysis reveals that PAX6 is required for normal transcription of pancreatic hormone genes and islet development. Genes Dev 11, 1662-73. 
Sapin, V., Bouillet, P., Oulad-Abdelghani, M., Dastugue, B., Chambon, P. and Dolle, P. (2000). Differential expression of retinoic acid-inducible (Stra) genes during mouse placentation. Mech Dev 92, 295-9.

Scardigli, R., Schuurmans, C., Gradwohl, G. and Guillemot, F. (2001). Crossregulation between Neurogenin 2 and pathways specifying neuronal identity in the spinal cord. Neuron 31, 203-17.

Schorle, H., Meier, P., Buchert, M., Jaenisch, R. and Mitchell, P. J. (1996). Transcription factor AP-2 essential for cranial closure and craniofacial development. Nature 381, 235-8.

Shi, D. and Kellems, R. E. (1998). Transcription factor AP-2gamma regulates murine adenosine deaminase gene expression during placental development. J Biol Chem 273, 27331-8.

Simpson, T. I. and Price, D. J. (2002). Pax6; a pleiotropic player in development. Bioessays 24, 1041-51.

Smart, I. H. (1973). Proliferative characteristics of the ependymal layer during the early development of the mouse neocortex: a pilot study based on recording the number, location and plane of cleavage of mitotic figures. $J$ Anat 116, 67-91.

Suzuki, S. C., Inoue, T., Kimura, Y., Tanaka, T. and Takeichi, M. (1997). Neuronal circuits are subdivided by differential expression of type-II classic cadherins in postnatal mouse brains. Mol Cell Neurosci 9, 433-47.

Tarabykin, V., Stoykova, A., Usman, N. and Gruss, P. (2001). Cortical upper layer neurons derive from the subventricular zone as indicated by Svetl gene expression. Development 128, 1983-93.

Thompson, D. A. and Gal, A. (2003). Vitamin A metabolism in the retinal pigment epithelium: genes, mutations, and diseases. Prog Retin Eye Res 22, 683-703.

Tibbles, L. and Wiley, M. J. (1988). A comparative study of the effects of retinoic acid given during the critical period for inducing spina bifida in mice and hamsters. Teratology 37, 113-25.

Treisman, J., Harris, E. and Desplan, C. (1991). The paired box encodes a second DNA-binding domain in the paired homeo domain protein. Genes Dev 5, 594-604. 
Turner, B. C., Zhang, J., Gumbs, A. A., Maher, M. G., Kaplan, L., Carter, D., Glazer, P. M., Hurst, H. C., Haffty, B. G. and Williams, T. (1998). Expression of AP2 transcription factors in human breast cancer correlates with the regulation of multiple growth factor signalling pathways. Cancer Res 58, 5466-72.

Vieira, A. V., Schneider, W. J. and Vieira, P. M. (1995). Retinoids: transport, metabolism, and mechanisms of action. J Endocrinol 146, 201-7.

Wald, G. (1968). Molecular basis of visual excitation. Science 162, 230-9.

Walther, C. and Gruss, P. (1991). Pax-6, a murine paired box gene, is expressed in the developing CNS. Development 113, 1435-49.

Warren, N., Caric, D., Pratt, T., Clausen, J. A., Asavaritikrai, P., Mason, J. O., Hill, R. E. and Price, D. J. (1999). The transcription factor, Pax6, is required for cell proliferation and differentiation in the developing cerebral cortex. Cereb Cortex 9, 62735.

Werling, U. and Schorle, H. (2002a). Transcription factor gene AP-2 gamma essential for early murine development. Mol Cell Biol 22, 3149-56.

Werling, U. and Schorle, H. (2002b). Conditional inactivation of transcription factor AP-2gamma by using the Cre/loxP recombination system. Genesis 32, 127-9.

Yoneshima, H., Yamasaki, S., Voelker, C. C., Molnar, Z., Christophe, E., Audinat, E., Takemoto, M., Nishiwaki, M., Tsuji, S., Fujita, I. et al. (2006). Er81 is expressed in a subpopulation of layer 5 neurons in rodent and primate neocortices. Neuroscience 137, 401-12.

Zhang, J., Hagopian-Donaldson, S., Serbedzija, G., Elsemore, J., Plehn-Dujowich, D., McMahon, A. P., Flavell, R. A. and Williams, T. (1996). Neural tube, skeletal and body wall defects in mice lacking transcription factor AP-2. Nature 381, 238-41.

Zhao, F., Satoda, M., Licht, J. D., Hayashizaki, Y. and Gelb, B. D. (2001). Cloning and characterization of a novel mouse AP-2 transcription factor, AP-2delta, with unique DNA binding and transactivation properties. J Biol Chem 276, 40755-60.

Zhao, F., Lufkin, T. and Gelb, B. D. (2003). Expression of Tfap2d, the gene encoding the transcription factor Ap-2 delta, during mouse embryogenesis. Gene Expr Patterns 3, 213-7. 
Zimmer, C., Tiveron, M. C., Bodmer, R. and Cremer, H. (2004). Dynamics of Cux2 expression suggests that an early pool of SVZ precursors is fated to become upper cortical layer neurons. Cereb Cortex 14, 1408-20.

Zimmerman, W. F. (1974). The distribution and proportions of vitamin A compounds during the visual cycle in the rat. Vision Res 14, 795-802. 


\section{Acknowledgements}

To Dr. Victor Tarakykin, for supervising my work and giving me the opportunity to do my $\mathrm{PhD}$ in his lab.

To Professor. Dr. Ernst August Wimmer for accepting to act as my Referee at the Faculty of biology and for his support with all formalities concerning the doctoral thesis. I would also like to thank Professor. Dr. Rüdiger Hardeland for being my Co-referee and for his critical evaluation of my thesis.

I offer my special thanks to Professor Dr. Walter Stühmer, for his constant help, moral support, encouragement and the friendly atmosphere he created during our seminars. His magnanimity is inspiring.

To my colleagues Camino de Juan, Anjana Nityanandam, Manuela Schwark and Malte Puhan for creating a friendly environment in the lab, and for fruitful scientific discussions.

To my long-standing friends Ravi Shankar, Rajesh, Vijaya Bhaskar, Arumugam and Naresh for motivating me to pursue a career in Germany and for supporting me morally and scientifically. 
To my friends Rajeshwara rao, Sunil, Raghu, Sudhakar, Srinivas and Narsimha for their help and support and making me feel at home in Goettingen.

To my wife Sailaja, for her constant support, patience and love.

To my parents, Nageswara Rao and Krishna Kumari, my uncle, Ramakrishna, my brother Vamshidhar and sister Vasanthi, who stood by me all the way through my career.

To all my friends in the Max Planck Institute for Experimental Medicine who have created an international atmosphere and never made me feel away from home. 


\section{Curriculum vitae}

\section{Sridhar Boppana}

Born on 16 July 1978, Vuyyuru, India.

\section{Education:}

Apr 1995 - Mar 1998: $\quad$ Bachelor of Science, Andhra University, India.

Apr 1998 - Nov 2000: $\quad$ Master of Science in Biochemistry, Periyar University, India.

Jun 2001 - Dec 2002: $\quad$ Diploma thesis, Prof. Dr. Paul Fisch, Pathology Institute, Freiburg, Germany.

Apr 2003 - Jan 2005: Jr. research fellow, Prof. Dr. Ralf Gold / Fred Lühder IMSF, Göttingen, Germany.

Feb 2005 - Present: $\quad$ PhD student, Prof. Dr. Walter Stühmer/ Victor Tarabykin, Max Planck Institute, Göttingen, Germany.

\section{Publications:}

Cellular retinaldehyde-binding protein (CRALBP) is a downstream target of Pax6 in regulating radial glial morphology (Manuscript in preparation for "The Journal of Neuroscience”).

Sridhar Boppana, John W Crabb and Victor Tarabykin

Smad-interacting protein-1 (Zfhx1b) acts upstream of Wnt signaling in the mouse hippocampus and controls its formation PNAS 2007

Amaya Miquelajauregui, Tom Van de Putte, Alexander Polyakov, Anjana Nityanandam, Sridhar Boppana, Eve Seuntjens, Anton Karabinos, Yujiro Higashi, Danny Huylebroeck, and Victor Tarabykin 
Post-transplantation lymphoproliferative disorder of recipient origin in a boy with acute T-cell leukemia with detection of B-cell clonality 3 months before stem cell transplantation.

The hematology journal 2005

http://www.haematologica.org/online/2005/ECR27/index.html

Udo Kontny, Sridhar Boppana, Andreas Jung, Heike Goebel, ${ }^{2}$ Brigitte Strahm, Anke Peters, Sabine Dormann, Martin Werner, Peter Bader, Paul Fisch, Charlotte Niemeyer 
........Chance favours the prepared mind Louis Pasteur 